\title{
Detection of triggered shallow slips caused by large earthquakes using L-band SAR interferometry
}

\author{
Satoshi Fujiwara* (10, Takayuki Nakano (D) and Yu Morishita(1)
}

\begin{abstract}
Interferograms pertaining to large earthquakes typically reveal the occurrence of elastic deformations caused by the earthquake along with several complex surface displacements. In this study, we identified displacement lineaments from interferograms; some of which occur on the shallow section of seismogenic faults. However, such displacements are typically located away from the hypocenter, and they are considered as triggered shallow slips. We found that the triggered shallow slips had a varied nature, as follows. (1) No evidence has yet been obtained regarding the generation of large seismic motion via triggered shallow slips; thus, their occurrence is seldom considered a cause of major earthquakes. However, we found that a movement of triggered shallow slip associated with an M 6-class earthquake occurred on an active fault that has previously caused an M 7-class earthquake. (2) At certain locations, several parallel displacement lineaments have been discovered. During the Kumamoto earthquake sequence in 2016, the strain created by the main shock and the motion of triggered shallow slips coincided at a specific location, resulting in the creation of parallel triggered shallow slips by the main shock. Conversely, at another location, the movements of the main shock and triggered shallow slips did not match, since the main shock was simply a trigger, whereas the latter parallel triggered shallow slips are likely a means for releasing previously accumulated strain. (3) The fault scaling law — which states that the length and displacement of a fault are proportional — does not hold true for triggered shallow slips. However, the parallel triggered shallow slips show a relationship between horizontal spacing and its displacement. This may be attributed to immobility in deep locations. These results lead to the following conclusions. Large earthquakes tend to trigger shallow slips on the pre-existing faults. Subsequently, these triggered shallow slips release accumulated strain by causing fault motions, which in turn result in displacement lineaments. The occurrence of such passive faulting creates weak, mobile fault planes that repeatedly move at the same location. These triggered shallow slips cause the diversity among active faults as a result.
\end{abstract}

Keywords: L-band SAR interferometry, JERS-1, ALOS, ALOS-2, Earthquake, Displacement lineament, Triggered shallow slip

\section{Introduction}

The interferometric synthetic aperture radar (InSAR) technology is generally used to detect surface deformations caused by earthquakes, volcanic activity, landslides, ground subsidence, etc. Typically, interferograms

*Correspondence: fujiwara-s2vq@mlit.go.jp

Geospatial Information Authority of Japan, 1 Kitasato, Tsukuba, Ibaraki 305-0811, Japan of large earthquakes reveal deformations caused by the main seismogenic faults. However, Fujiwara et al. (2000b) observed the occurrence of several small displacement lineaments (hereinafter referred to as "DLs") in interferograms obtained from an L-band SAR satellite from the Kobe earthquake of 1995. Since the location of some of these DLs coincided with those of active faults, the DLs likely appeared to be triggered shallow slips (hereinafter referred to as "TSSs"). Subsequently, Fujiwara et al. 


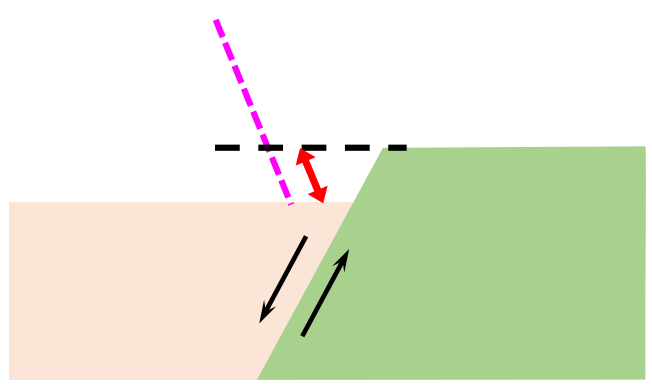

a A fault reaches the surface

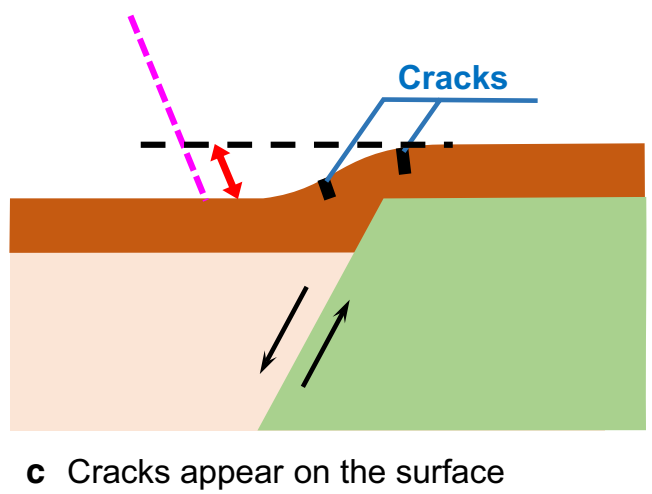

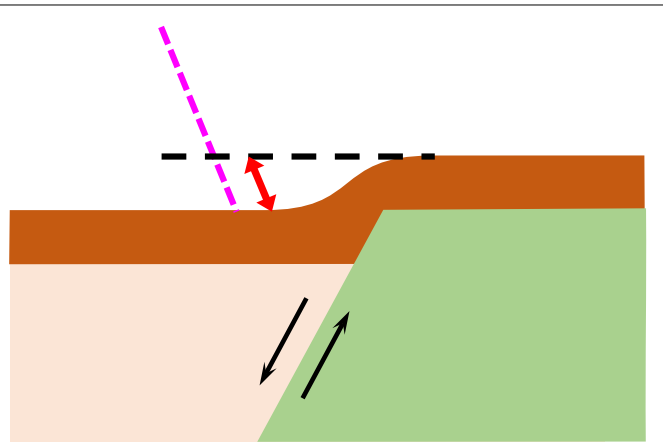

b A fault does not reach the surface

\section{Displacement measured by InSAR}

I. Radar line-of-sight (LOS)

Fig. 1 Schematic explanation of displacement measurement using InSAR for surface fault motion. InSAR can capture displacements along the radar line-of-sight caused by fault motion without being affected by deposits or cracks

(2000a), Nishimura et al. (2008), Fukushima et al. (2013), Kaneko et al. (2015), Fujiwara et al. (2016), and Fujiwara et al. (2019) reported the occurrence of several similar DL features caused by other large earthquakes.

Fujiwara et al. (2000a) classified small-scale displacement anomalies in interferograms, including co-seismic deformation of large earthquakes into six categories: (1) main earthquake faults and their branched subfaults, (2) aftershock faults, (3) earthquake faults indirectly related to the main shock, (4) landslides and/or creep along geologically weak surfaces caused by strong earthquake motion, (5) elastic seismic deformation on steep topographies, and (6) noise in the interferograms. DLs clearly correspond to fault-like displacements that appear to be away from the main earthquake's faults in interferograms. Displacements considered in this study likely belong to Category (3), as described above. TSSs were reported in a number of studies (e.g., Allen et al. 1972; Sangawa et al. 1985; Sieh 1982). Sangawa et al. (1985) reported that TSSs did not independently cause a large earthquake, and that the observed fault motion was caused by other large earthquakes. Recent work has found that a shallow slip can also be triggered by earthquakes that occurred thousands of kilometers away (e.g., Tymofyeyeva et al. 2019). Fujiwara et al. (2016) reported the occurrence of more than 230 DLs during the Kumamoto earthquake sequence of 2016, and this finding drew considerable research attention during the development of the InSAR technology.

A large earthquake causes crustal deformation over a wide area, and exposed faults can be identified by ground surveys (e.g., Shirahama et al. 2016) and by aerial photographs (e.g., Nakano et al. 2019; Yoshida et al. 2016). However, it is difficult to perform a comprehensive and efficient fault analysis using ground surveys and/or aerial photographs owing to the inability of both methods to detect small displacements (measuring several $\mathrm{cm}$ ) over the surveyed areas. Since most ruptures do not exist as continuous cracks (Fig. 1), it is difficult to comprehend the characteristics of DLs using ground surveys and/or aerial photographs exclusively. Satellite-based remote-sensing techniques are capable of mapping deformation fields over large areas with high accuracy (precision of up to few $\mathrm{cm}$ ), without the need for ground-based measurement facilities.

The Japanese Earth Resources Satellite (JERS-1), launched in 1992 by National Space Development Agency of Japan (NASDA; now known as Japan Aerospace Exploration Agency, JAXA), was equipped with an L-band SAR sensor. It acquired a large volume of 
data globally during 1992 and 1998. In addition, JAXA has launched two L-band SAR satellites-Advanced Land Observing Satellite (ALOS) in 2006 and ALOS-2 in 2014.

The wavelength of microwaves emitted by the JERS-1, ALOS, and ALOS-2 satellites is advantageous for performing surface-displacement observations. The L-band InSAR is generally appropriate for detecting surface displacements-even in vegetated areas-owing to its high interferometric coherence compared to C- and X-band microwaves (e.g., Morishita and Hanssen 2015; Rosen et al. 1996). Because Japan comprises a mountainous terrain with heavy vegetation, the above-mentioned capability of L-band InSAR facilitates surveying the crustal deformation of a large region of interest. Stacking multiple interferograms (Fujiwara et al. 1998) and/ or use of time-series analysis techniques, such as SBAS (Berardino et al. 2002) and PSInSAR (Ferretti et al. 2001), can improve interferogram quality even at shorter wavelengths. However, obtaining a sufficient number of InSAR image pairs for stacking and performing timeseries analyses is often considered impossible because of the limited number of satellite observations for a particular earthquake. Therefore, time-series analyses were not performed in this study. Moreover, in satellites such as ALOS-2, the frequency of observations outside Japan may not necessarily be high. However, L-band InSAR enables effective processing of information even in areas mapped with a low observation frequency.

The L-band InSAR is one of the best tools for the detection of details concerning the crustal deformation caused by earthquakes. The improvement in performance of the ALOS-2 satellite and other short-term intensive observations has revealed the occurrence of several phenomena, especially during the 2016 Kumamoto earthquake sequence (Fujiwara et al. 2016; 2017a; Morishita 2019). This study reviews these past cases of DL detection; in addition, new analyses have been performed. Subsequently, in the light of these analyses, this study clarifies the nature of TSSs. Since the causes of linear displacements observed in interferograms cannot be specified, such lineaments are referred to as DLs. The purpose of this study is to extract DLs and discuss TSS properties.

\section{Data and methods}

In this study, we used L-band SAR data obtained from JERS-1, ALOS, and ALOS-2 satellites. SAR data were processed as described by Fujiwara et al. (2016; 2017b; 2019). DL detection involves determining a linear displacement shift in interferograms that reveal a change in the distance between the ground target and satellites along the radar line-of-sight (LOS). DLs may not be found from a specific direction because the displacement direction may be nearly perpendicular to the radar LOS. Therefore, it is desirable to use interferograms captured along different LOS directions if possible.

In this study, DLs were mapped on interferograms. The obtained LOS displacement data mainly comprised coseismic displacements due to seismogenic faults; other localized signals, and noise, such as atmospheric noise. Although significant atmospheric noise can be captured in interferograms, we assumed short-wavelength lineaments in interferograms to be unrelated to atmospheric noise owing to the latter being characterized by long wavelengths (Fujiwara et al. 1998). Moreover, lineaments were obtained from interferograms recorded on different dates; thus, the occurrence of identical atmospheric effects on different data acquisition dates is highly unlikely (Fujiwara et al. 2016). In principle, lineated features in the radar phase may be an atmospheric artifact if they correlate with topography (e.g., a valley or a ridge). However, we consider that the DLs are not an artifact because they are present in all co-seismic interferograms but not in any pre- and post-seismic interferograms (Fialko et al. 2002), and other lineated features are not found in steeper terrains in their vicinity. In addition, digital elevation models were used in this study to remove topographic effects. These digital elevation models afford sufficient DL detection accuracy (Fujiwara et al. 2016; 2017b). For the above-mentioned reasons, the long and clearly visible DLs identified in this study were considered to have been caused by seismic activities.

There exist three major methods for DL identification in interferograms. The first involves directly reading phase discontinuity from interferograms. L-band SAR interferograms generally have much higher quality than those obtained from other satellites. In addition, acquisition of images from different satellite positions facilitated easy DL identification. In cases wherein DL displacement exceeded several centimeters, this identification method was used. The second method uses surface-displacement gradient maps or high-pass filtered maps for DL visualization (Fujiwara et al. 2000a, b; Price and Sandwell 1998). In cases involving small displacements, gradient and/or high-pass filtered maps are helpful in lineament identification. In cases involving extremely small displacements, such as $1-2 \mathrm{~cm}$, these maps become necessary for DL identification. The third method involves using interferogram coherence maps as a supplementary tool for identifying DLs (Fujiwara et al. 2016).

Although phase unwrapping is essential for stacking and phase gradient analysis, it should be noted that phase unwrapping is not applied to all interferograms due to decorrelation. Essentially, we utilized the original wrapped interferograms to identify DLs because of the complexity of phase discontinuities in the presence 
of a number of DLs and decorrelations. Since linearity is visually determined and linearity judgments may therefore change from one analyst to another, an objective judgment standard should be created for reference in all cases, which can be used even when the displacement is small and/or the linearity is not clear.

A single InSAR image is limited to a radar LOS direction and cannot be separated to the vertical and horizontal displacements without assumptions. Multi-angle observations from ascending and descending orbits over short time periods facilitate 2.5-D (Fujiwara et al. 2000a, b) and/or 3D (e.g., Morishita et al. 2016) surfacedeformation analyses. Because of the inclination of the ALOS-2 satellite orbit, the ascending and descending orbits are not parallel, and the combination of left and right observations enables us to detect crustal deformation in 3D. Although such analysis methods are not always necessary for DL detection, they are useful for quantitatively analyzing displacement directions. For such analyses, however, we not only need the multi-angle observations but also to unwrap the interferograms; then these analyses are limited.

Fujiwara et al. (2016) referred to lineaments as "linear surface ruptures"; however, owing to the difficulty involved in determining whether actual ruptures exist, we refer to these features as DLs, which demonstrate a sharp contrast in phase changes. They are derived from linear phase discontinuities and/or offsets revealing displacements in interferograms. Notably, these features are not the same as fault ruptures, owing to the fact that they are derived from displacements. In general, ruptures do not always appear directly on a surface (see Fig. 1).

Because a major objective of this study is to investigate the motion of hidden faults, we attempted to remove displacements demonstrating intricately bent and/or circular curves, such as those indicating landslides, liquefaction (Nakano et al. 2019), and lateral spreading (Fujiwara et al. 2017a). Landslides can be easily identified because they tend to appear as circular mass movements in interferograms originating from a hillside or hilltop and sliding down.

\section{Examples of DLs detected by L-band InSAR}

This section introduces major DLs detected using L-band InSAR.

\section{$M_{\mathrm{w}} 6.9$ Kobe earthquake of 1995}

Using JERS-1 InSAR data, Fujiwara et al. (2000b) reported the appearance of nearly $30 \mathrm{DLs}$ (Fig. 2) caused by the Kobe earthquake $\left(M_{\mathrm{w}} 6.9\right)$ that occurred on January 17, 1995. As observed, most of these DLs coincided with known active faults. The Nojima fault-an exposed active fault that is likely connected to the main seismogenic faults-exhibits the occurrence of an excessively large displacement, and it therefore cannot be detected from interferograms. Fujiwara et al. (2000b) also reported the occurrence of strong seismic vibrations in the DLs found in the region surrounding the main faults. Accordingly, there exists a possibility that hidden faults accelerate the main seismic vibrations.

\section{$M_{\mathrm{w}} 5.9$ Northern Iwate earthquake of 1998}

Using JERS-1 InSAR data again, Fujiwara et al. (2000a) reported the appearance of 15 DLs (Fig. 3) caused by the Northern Iwate earthquake $\left(M_{\mathrm{w}} 5.9\right)$ that occurred on September 3, 1998. Their study was the first to perform 2.5-D analyses to examine DL movements. Fujiwara et al. (2000a) reported that the movement of some DLs coincides with an increase in the Coulomb failure function (delta CFF) of the modeled main earthquake fault, whereas the other DLs did not demonstrate this coincidence. Moreover, some DLs closely correlated with local volcanic activities.

\section{$M_{\mathrm{w}} 6.7$ Chuetsu-oki earthquake of 2007}

Using ALOS InSAR data, Nishimura et al. (2008) reported the occurrence of a DL approximately $12-25 \mathrm{~km}$ away from the epicenter of the Chuetsu-oki earthquake $\left(M_{\mathrm{w}}\right.$ 6.7), which occurred on July 16, 2007. Figure 4 depicts the interferogram and the DL therein. The shape of the displacement resembles that of a local uplift (1.5$\mathrm{km}$ wide and $15-\mathrm{km}$ long), and this is not likely a result of simple fault motion. The existence of this uplift indicates an episodic growth of active folds, and the triggering of creep acceleration can probably be attributed to an increase in static stress due to the earthquake (Nishimura et al. 2008).

\section{$M_{\mathrm{w}} 6.6$ Iwaki earthquake of 2011}

Using ALOS InSAR data, Fukushima et al. (2013) reported the appearance of not only the main earthquake faults but also secondary-earthquake faults caused by the Iwaki Earthquake $\left(M_{\mathrm{w}} 6.6\right)$ that occurred on April 11, 2011. Figure 5 depicts the DLs identified in this study.

\section{Kumamoto earthquake sequence of $\mathbf{2 0 1 6}$}

Using ALOS-2 InSAR data, Fujiwara et al. (2016) reported the appearance of more than 230 DLs (Fig. 6) caused by the Kumamoto earthquake sequence of 2016, with the largest earthquake of $M_{\mathrm{w}} 7.0$ occurring on April 16, 2016. Reported DLs were modified in this study. Detailed analyses are described in the next section.

\section{$M_{\mathrm{w}} \mathbf{5 . 6}$ Northern Osaka earthquake of $\mathbf{2 0 1 8}$}

On June 18, 2018, an $M_{\mathrm{w}}-5.6$ earthquake hit the northern Osaka prefecture in Japan at a depth of approximately 

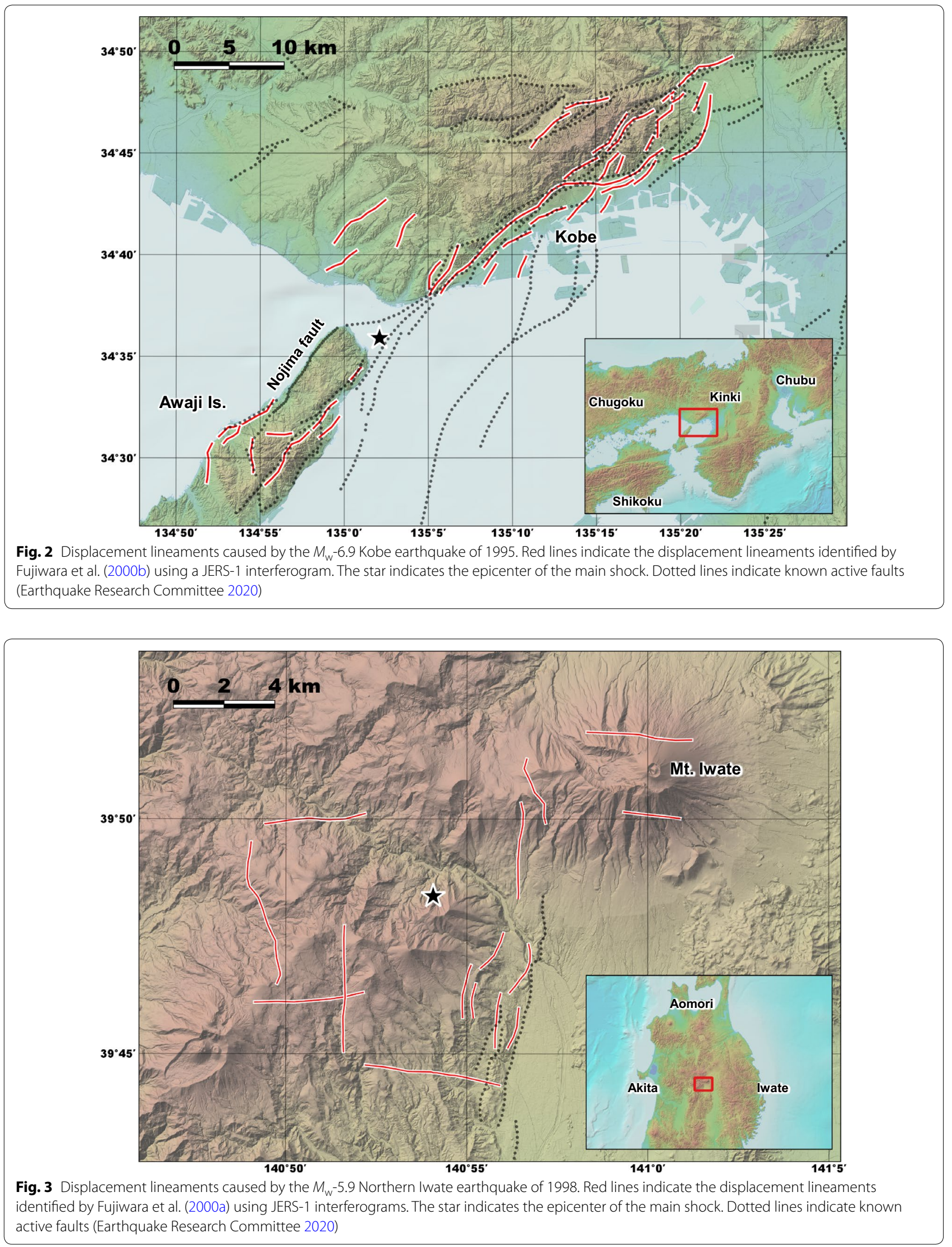

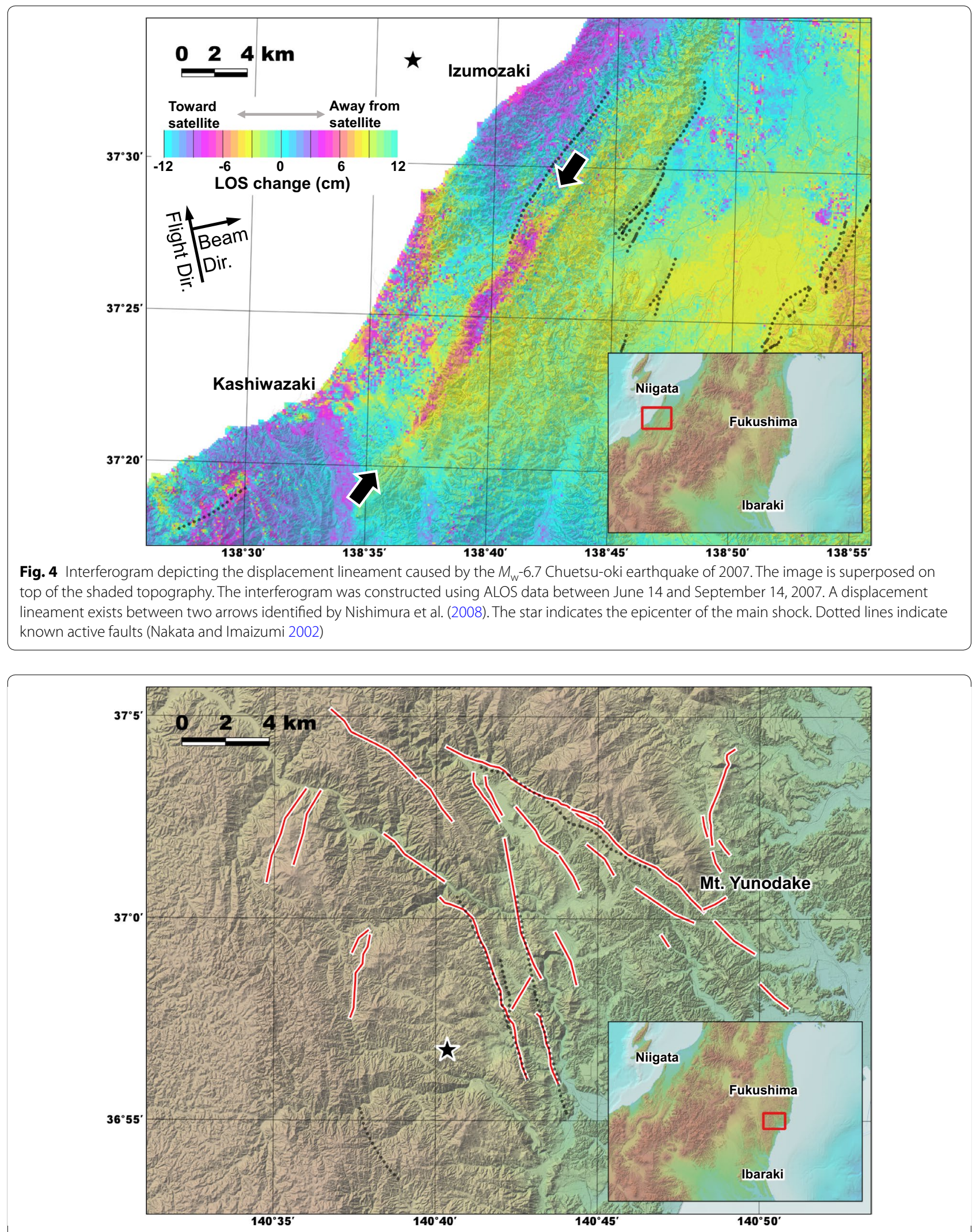

Fig. 5 Displacement lineaments caused by the $M_{w}-6.6$ Iwaki earthquake of 2011. Red lines indicate the displacement lineaments identified in this study using ALOS interferograms. The star indicates the epicenter of the main shock. Dotted lines indicate known active faults (Nakata and Imaizumi 2002) 
$15 \mathrm{~km}$ (Earthquake Research Committee 2018), and the focal mechanism demonstrated a compression axis along a WNW-ESE direction. The Arima-Takatsuki fault zone extending along the $\mathrm{E}-\mathrm{W}$ direction had been identified in the region surrounding the epicenter. However, the shallow part of the fault zone was not considered to be the seismogenic fault (Kato and Ueda 2019).

Figure $7 \mathrm{a}$ depicts an interferogram captured by the ALOS-2 satellite. The crustal deformation caused by the seismogenic fault was approximately measured to be less than $2-3 \mathrm{~cm}$. However, a very small linear feature can be found between the arrows shown in Fig. 7a. We identified a DL using a displacement gradient map (Fig. 7b). Among the earthquakes for which we have identified DLs, the northern Osaka earthquake of 2018 was of the smallest magnitude. Known active faults belonging to the ArimaTakatsuki fault zone are depicted in Fig. 7c. The eastern part of the DL can be clearly observed and coincides with a known active fault-Makami fault. The Makami fault demonstrated a movement of approximately $1 \mathrm{~m}$ at the time of a large historic earthquake-the Keicho-Fushimi earthquake of 1596-having a moment magnitude of approximately 7 (Earthquake Research Committee 2001). The concerned DL demonstrated right-lateral movement coinciding with the historical movement of the Makami fault. This is important evidence in that even a major active fault causing an $\mathrm{M} 7$-class earthquake can move as a DL.

\section{$M_{\mathrm{w}} 6.6$ Hokkaido Eastern Iburi earthquake of 2018}

Fujiwara et al. (2019) reported the appearance of DLs representing secondary earthquake faults to the west of the epicenter of the $M_{\mathrm{w}}-6.6$ Hokkaido Eastern Iburi earthquake of 2018 that occurred on September 6, 2018. The observed DLs (Fig. 8) reveal reverse fault motion with low dip angles, and they appear to be geographic extensions of known active faults. However, it is unlikely that these displacements are directly connected to the seismogenic fault of the main earthquake, because the seismogenic fault demonstrated a high dip angle (Fujiwara et al. 2019). Although there is no evidence that the observed DLs generated strong seismic waves during the main earthquake, they may probably represent active fault traces and might act as sources of large earthquakes in the future. Therefore, such DLs can be used to identify potentially dangerous hidden active faults.

In the case of this earthquake, no DL traces were observed on the ground. As depicted in Fig. 1, if the fault does not reach the surface, its surface observation by ground survey becomes difficult. However, InSAR can capture the occurrence of entire DLs. In particular, L-band InSAR can obtain data over the entire surface, and it is extremely effective for identifying DLs.
$M_{\mathrm{w}} 7.8$ South Island (New Zealand) earthquake of 2016 Morishita et al. (2018) constructed interferograms pertaining to the $M_{\mathrm{w}}-7.8$ earthquake that hit South Island in New Zealand on November 13, 2016. Mapped DLs are depicted in Fig. 9. As pointed out by Morishita et al. (2018), some DLs are located near known active faults, and their strike directions demonstrate some regularity. In addition, the regional tectonic stress field appears to affect these DLs.

\section{$M_{\mathrm{w}} 7.3$ Iran-Iraq earthquake of 2017}

Kobayashi et al. (2018a) constructed interferograms pertaining to the $M_{\mathrm{w}}-7.3$ earthquake that occurred along the Iran-Iraq border earthquake on November 12, 2017. Mapped DLs of the same are depicted in Fig. 10. As can be observed, most DLs are secondary faults, which are not directly related to the main earthquake. However, their slip is probably triggered by the main earthquake.

\section{Ridgecrest earthquake sequence of 2019}

The 2019 Ridgecrest earthquake sequence that hit California on July 4-5, 2019, comprised three main shocks with moment magnitudes of 6.4, 5.4, and 7.1 (U.S. Geological Survey 2019). The Geospatial Information Authority of Japan (2019) constructed interferograms for these earthquakes, and we detected DLs from the images. $\mathrm{Xu}$ et al. (2020) got better quality images using C-band InSAR because the area has little vegetation.

Figure 11 depicts the interferogram and DLs. Unlike other cases discussed in this section, seismic faults appeared directly on the surface during this earthquake sequence. As observed, the displacement of the northern seismogenic fault was large, and the location of the surface fault could not be accurately determined-even in cases wherein the L-band InSAR was employedowing to the occurrence of decorrelations. A lineament extending along the southwest direction was surrounded by large deformation fringes, and displacements likely occurred at places with depths measuring several kilometers. Therefore, these DLs look slightly different compared to general DLs and were likely caused by the seismogenic faults directly. In addition, other smaller DLs can be observed in the figure.

\section{Detailed analyses of the Kumamoto earthquake sequence of 2016}

Fujiwara et al. (2016) demonstrated that DLs caused by the 2016 Kumamoto earthquake sequence tend to run parallel to each other with nearly constant horizontal spacing. They can therefore be classified into several groups based on their locations and features. Two regions-around the Suizenji Park and northwest of the outer rim of Aso caldera (hereinafter called 
"NW-Aso")- are analyzed in detail in this study. Several parallel DLs have appeared at these places.

Figure 12 depicts epicenters of earthquakes occurring after April 14, 2016, including aftershocks, and postseismic surface deformation detected by InSAR, respectively (Fujiwara et al. 2016). For most DLs, the observed distribution matches well with the aftershock distribution. Corresponding focal mechanisms are depicted in Fig. 12c, and as observed, the focal mechanism of aftershocks as well as the strike and displacement directions of DL agree well with the right-lateral movement, especially in the northeast and southwest regions depicted in Fig. 12c. However, there exist places, such as NW-Aso, where DL concentration occurred, despite no occurrence of aftershocks.

Post-seismic deformation (Additional file 1: Fig. S1) was observed in regions surrounding the Suizenji Park, whereas no such deformation was observed in NW-Aso. Further, several aftershocks were recorded around the Suizenji Park, whereas no aftershocks were observed in NW-Aso. Fujiwara et al. (2016) suggested that there exists a significant difference between DL causes observed at Suizenji Park and NW-Aso. DLs at both these sites demonstrate graben formation. In the Suizenji Park region, however, some deformation mechanism was observed to be active after the main shock (Additional file 1: Fig. S1; Fujiwara et al. 2016), whereas no significant post-seismic deformation or aftershocks were observed in NW-Aso. The remainder of this section examines differences between these DL groups.

\section{Around Suizenji Park}

Figure 13 depicts DLs around Suizenji Park along with a high-pass filtered up-down displacement map (Fujiwara et al. 2016) obtained using three-dimensional (3D) InSAR (Morishita et al. 2016; Morishita 2019). Figure 14 depicts the surface strain (extension and contraction) and dilatation values calculated using a 3D deformation map for co-seismic displacement (Additional file 1: Fig. S2). As can be observed, the surface strain clearly demonstrates a dominant ENE-WSW extension in this region. Therefore, large horizontal displacements along the ENE direction owing to right-lateral movement of the Futagawa fault that exists east of this region can be considered a probable reason behind DL occurrence. Because larger horizontal displacements exist in the eastern part, this region is characterized by an ENE-WSW extension field and displacements with a graben or half-graben structure. In addition, the observed DL movement coincides with increased delta CFF of main seismogenic faults, especially at shallow locations (Additional file 1: Fig. S3).
On the other hand, it is a natural predisposition to assume that faults in this region existed and that an earthquake led to their passive displacement as the DLs. In fact, some DLs can be observed to have been distributed along active faults described in the 1:25,000 active fault map "Kumamoto (revised ed.)" (Kumahara et al. 2017) published after the earthquake (Fig. 13). Subsequently, we estimated the existence of a shallow subsurface structure around Suizenji Park using borehole data and investigated the existence of faults that predispose to DLs associated with this earthquake.

Figure 13 depicts positions of borehole data acquisition and survey lines (A1-A9 and B1-B10) that connect them. Borehole data were obtained from the Geo-Station (National Research Institute for Earth Science and Disaster Resilience 2016). Figure 15a shows the vertical-displacement cross-section of InSAR, topographic cross-section, and borehole column diagrams along survey lines A1-A9 as well as the subsurface formation estimated using this information. The borehole columns, i.e., from the surface to approximately $-20 \mathrm{~m}$ above sea level, are divided into gravelly soil layers with $\mathrm{N}$ values exceeding 50 with sandy and silty soil layers above them. According to Tajiri et al. (1998), this region contains alluvium deposited from the surface to approximately $0 \mathrm{~m}$ above sea level and a terrace gravel layer between $0 \mathrm{~m}$ and $-20 \mathrm{~m}$ above sea level. Aso-3 or Aso-4 pyroclastic flow deposits are distributed below $-20 \mathrm{~m}$ above sea level. The sandy and silty soil layers depicted in Fig. 15a are considered alluvial layers and the gravelly soil layers are considered terrace gravel layers.

From Fig. 15a, using the top elevation of the gravelly soil layer as key, vertical displacements of the stratum can be recognized on the west of boreholes A2 and A6. As observed, the position and orientation of vertical displacements exist in harmony with those of DLs detected by InSAR. In particular, an active fault can be confirmed to the southwest of borehole A6 (Fig. 13) with a high probability of fault existence. Existence of a graben structure can be confirmed between boreholes A2 and A6, and the subsidence between boreholes A2 and A6 can be observed in the subsurface region. In addition, the position and direction of faults exist in harmony with those of DLs to the west of borehole A7. The fault is likely to correspond to the northern extension of the active fault identified in the south of this borehole (Fig. 13). In addition, stratum displacements to the west and east of boreholes A3 and A4, respectively, as well as the DL locations between boreholes A8 and A9 could not be confirmed.

Figure $15 \mathrm{~b}$ depicts the vertical-displacement crosssection, topographic cross-section, and borehole column 


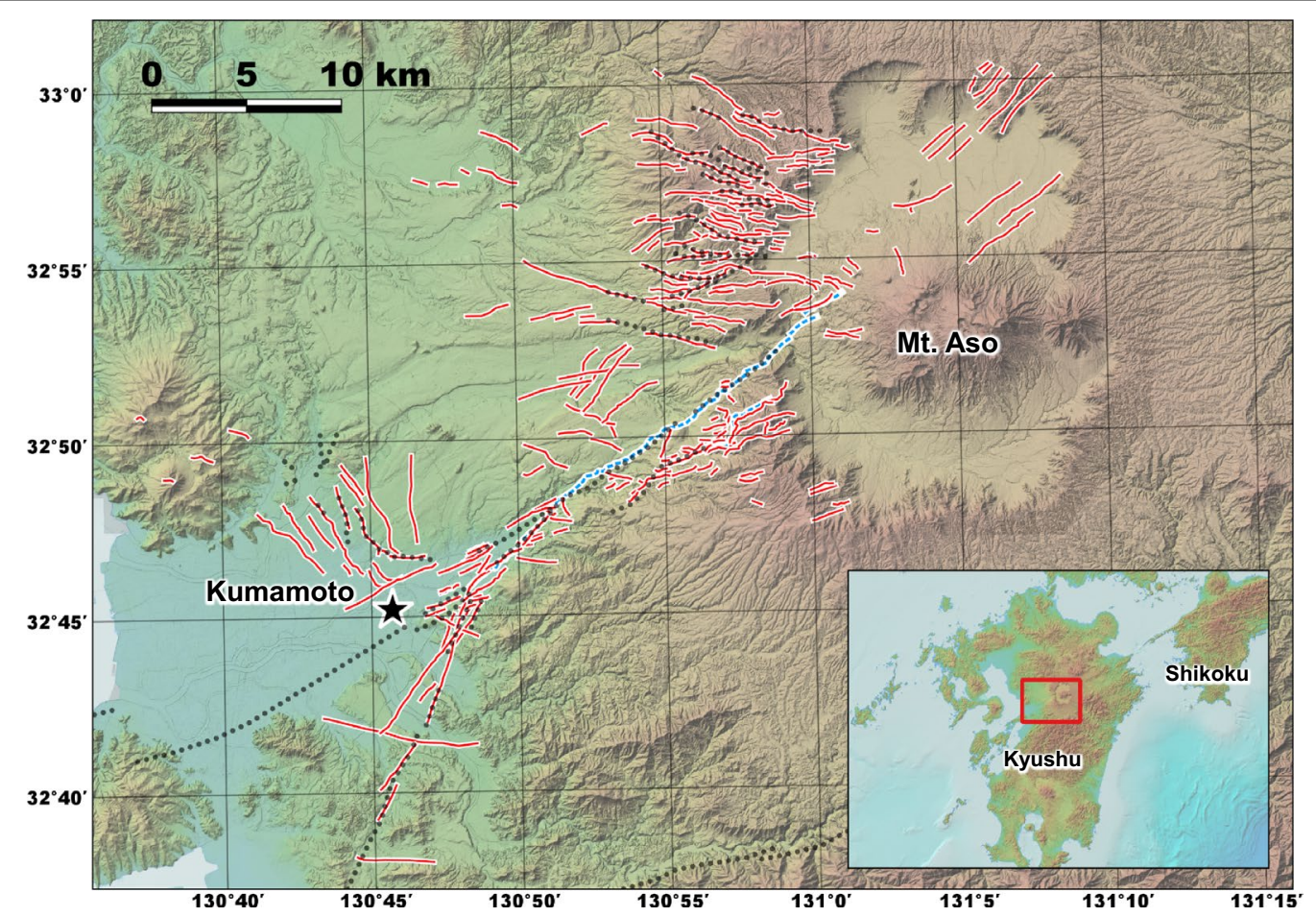

Fig. 6 Displacement lineaments caused by the Kumamoto earthquake sequence of 2016. Red lines indicate the displacement lineaments identified by Fujiwara et al. (2016) and modified in this study using ALOS-2 interferograms. Blue broken lines indicate large discontinuities observed in ALOS-2 pixel offset images. The star indicates the epicenter of the main shock. Dotted lines indicate known active faults (Earthquake Research Committee 2020; Kumahara et al. 2017; Suzuki et al. 2017)

diagrams along survey lines B1-B10 along with subsurface formation estimated using this information. ${ }^{1}$ The borehole column diagrams reveal that although the volcanic-ash layer remains partially sandwiched from the surface to approximately $-20 \mathrm{~m}$ above sea level, the borehole columns remain roughly identical to those corresponding to survey lines A1-A9. However, considering the geological profile of Tajiri et al. (1998), the hard rock at B10 at a depth of more than $15 \mathrm{~m}$ above sea level is Aso-4 pyroclastic flow deposit. To be precise, the borehole columns largely comprise a gravelly soil layer with $\mathrm{N}$ value exceeding 50 , capped by sand and silty soil layers at the top. Similar to the case described above, when the top elevation of the gravelly soil layer is considered key, vertical displacement of the stratum can be recognized to the west of borehole B7 and between boreholes B8 and B9. The position and orientation of these vertical displacements of the stratum were observed to be consistent with those of DLs detected by InSAR, thereby confirming the existence of a fault. In particular, an active fault

\footnotetext{
${ }^{1}$ The borehole head elevation of the original data of borehole B9 is indicated as $0.29 \mathrm{~m}$. However, it was judged that the borehole head elevation and borehole head depth were erroneously described because the shallow soil was considered surface soil. In Fig. 16a, the top of the borehole column was placed near the ground surface.
}

can be confirmed between boreholes B8 and B9 with a high probability of fault existence because the active fault was described by Kumahara et al. (2017) and Goto et al. (2017). ${ }^{2}$ Likewise, no displacement of the geological formation could be confirmed at DL locations detected to the east and west of boreholes $\mathrm{B} 6$ and $\mathrm{B} 9$, respectively. Although no DL was detected between boreholes B7 and B8, the existence of faults with vertical displacement was indirectly confirmed by the top elevation of the gravelly soil layer. Since there exists an active fault to the north of the gap between boreholes B7 and B8 (Fig. 13), the fault likely extends to the south as well.

In view of the above results, DLs detected by InSAR were active faults, as reported by Kumahara et al. (2017), unknown faults, or passively displaced faults caused by the Kumamoto earthquake sequence.

It is noteworthy that irrespective of DLs demonstrating similarities in length and displacement on

\footnotetext{
${ }^{2}$ According to Goto et al. (2017), analysis of borehole data around the area showed that the upper surface of the Aso-4 pyroclastic flow deposit, which is distributed 10 to $20 \mathrm{~m}$ underground, is displaced vertically by approximately $10 \mathrm{~m}$ due to this active fault. Since the borehole data and cross-sectional position used in this study are different from that of Goto et al. (2017), the stratum composition and the amount of vertical displacement do not match, but we are certain that the vertical displacement exists underground at this site.
} 

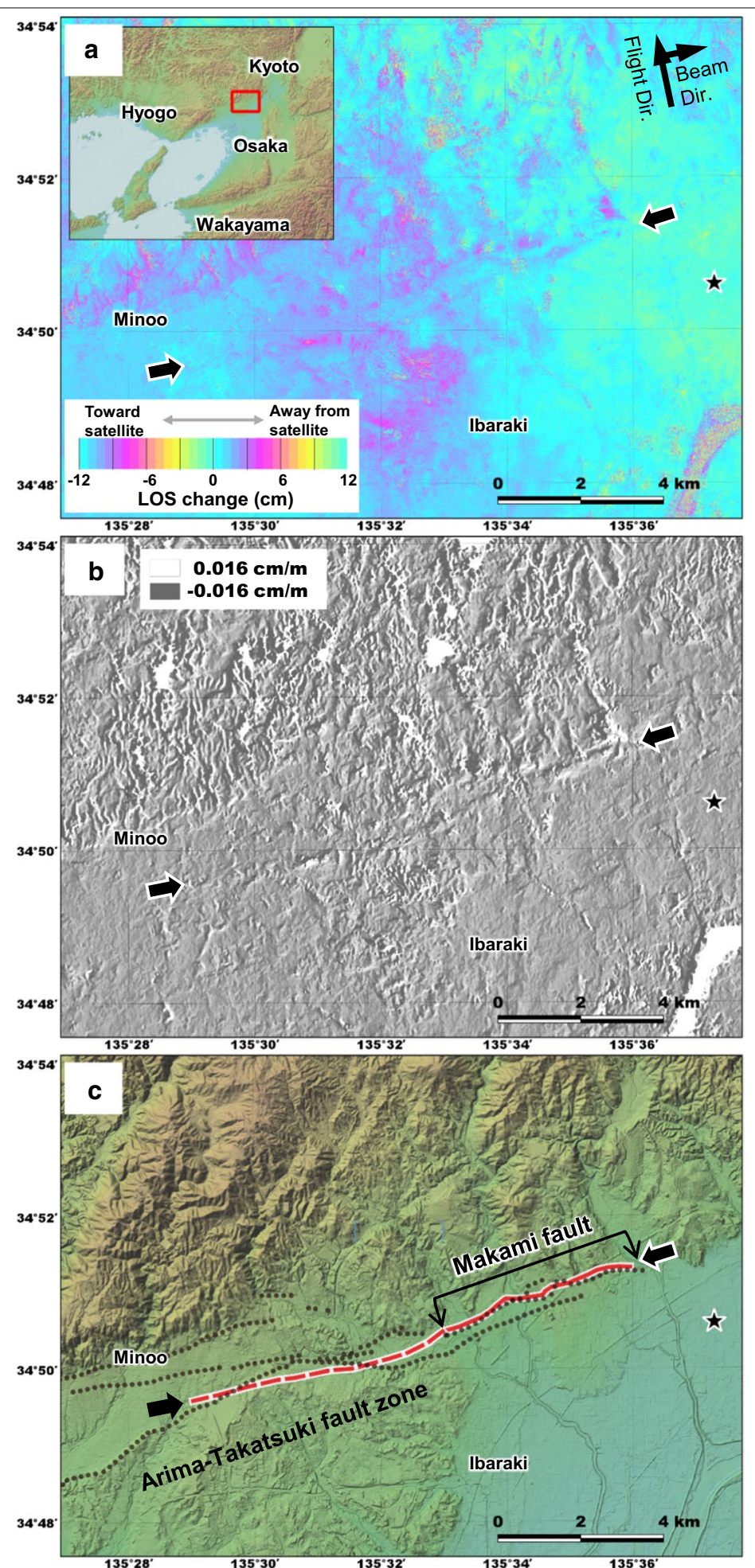

Fig. 7 Displacement lineament caused by the $M_{w}-5.6$ Northern Osaka earthquake of 2018. a Interferogram depicting surface deformation. The interferogram was constructed using ALOS-2 data captured between April 9 and June 18, 2018. A displacement lineament exists between the two arrows as identified in this study. The star indicates the epicenter of the main shock. $\mathbf{b}$ Gradient shade map of ALOS-2 InSAR line-of-sight displacement. Gradients along $60^{\circ}$ and $150^{\circ}$ (positive clockwise from north to east) directions were calculated and the one that is larger in magnitude was mapped. There exist two arrows indicating the same position, as in a. c The red line indicates a displacement lineament identified in this study. The red broken line indicates a displacement lineament, the existence of which is uncertain owing to small displacements. The star indicates the epicenter of the main shock. Dotted lines indicate known active faults (Okada et al. 2008) 


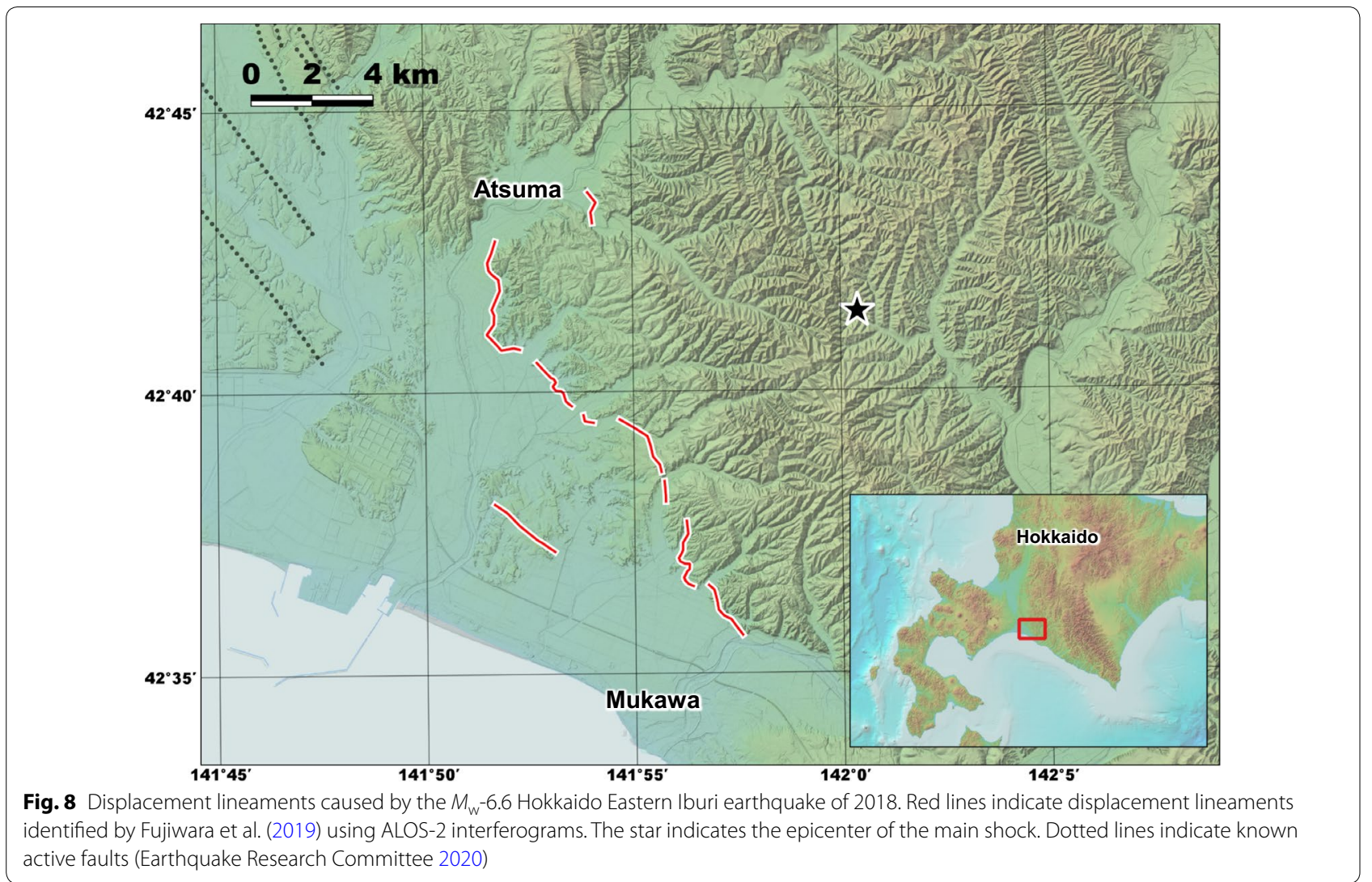

active faults (Earthquake Research Committee 2020)

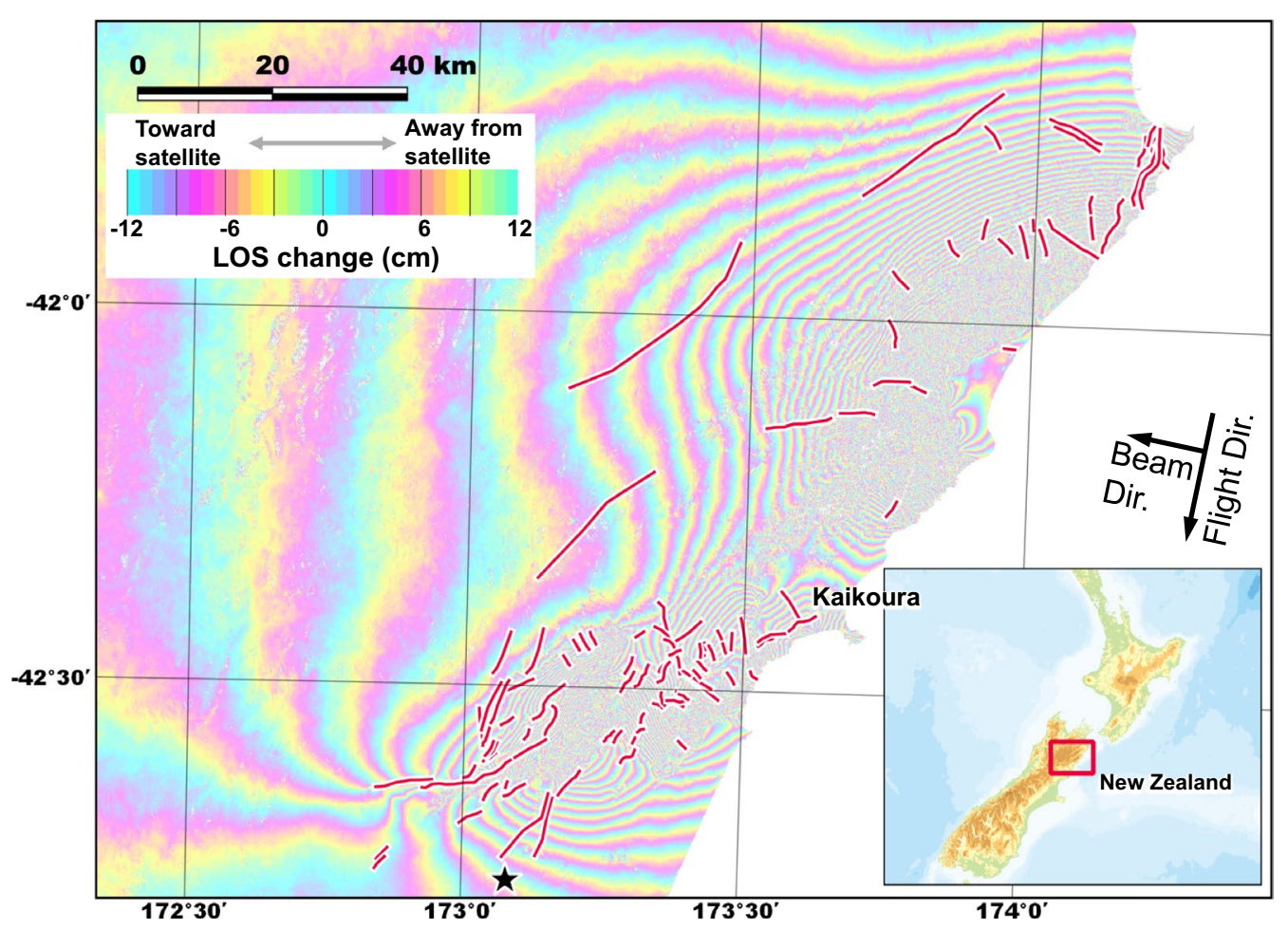

Fig. 9 Interferogram indicating displacement lineaments caused by the $M_{w}-7.8$ South Island (New Zealand) earthquake of 2016. The interferogram was constructed using ALOS-2 data captured between October 23 and December 4, 2016. Red lines indicate displacement lineaments identified by Morishita et al. (2018) and modified in this study. The star indicates the epicenter of the main shock 


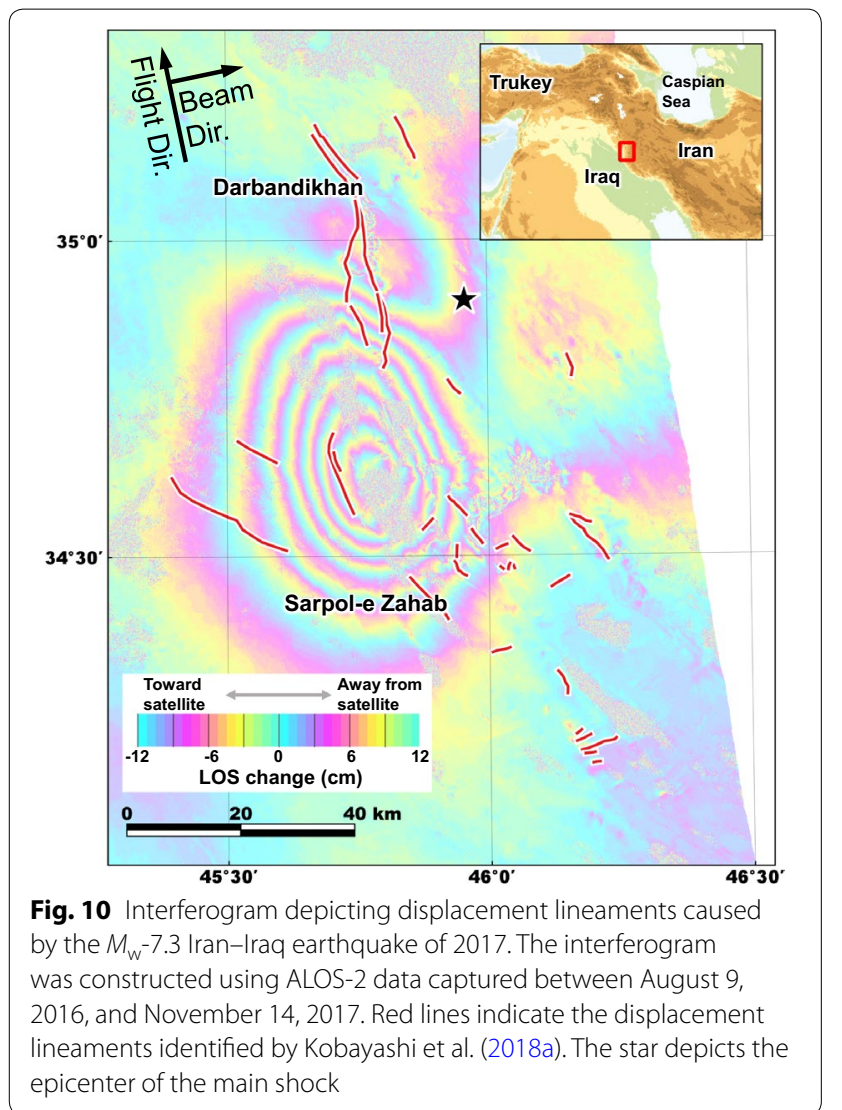

interferograms, their respective underground structures differ significantly. It is unclear whether this is due to insufficient borehole data or if DLs move during an earthquake without necessarily being dependent on their underground structures. Therefore, further research must be performed in this regard.

\section{Northwest of outer rim of Aso caldera (NW-Aso)}

In this study, several dozen DLs were observed in the NW-Aso region. These DLs were generally aligned along the WNW-ESE direction and comprise typical dipslip displacements. Figure 16a depicts DLs observed in NW-Aso along with a high-pass-filtered up-down displacement map, whereas Fig. 16b depicts the difference between vertical displacements to the north and south of each DL. The largest up-down displacement gap (exceeding $40 \mathrm{~cm}$ ) was observed in the southern part of NW-Aso. Two typical cross-sections indicated in Fig. 16a are depicted in Fig. 17.

The DL group in NW-Aso was further divided into two groups-northwest and southeast-the mainly comprised dip-slip displacements comprising downward movement of the southern and northern DL sides, respectively (Fujiwara et al. 2016). The observed displacement patterns demonstrate saw-tooth shapes, directions of which differ between the two groups (Fig. 17). Suzuki et al. (2017)

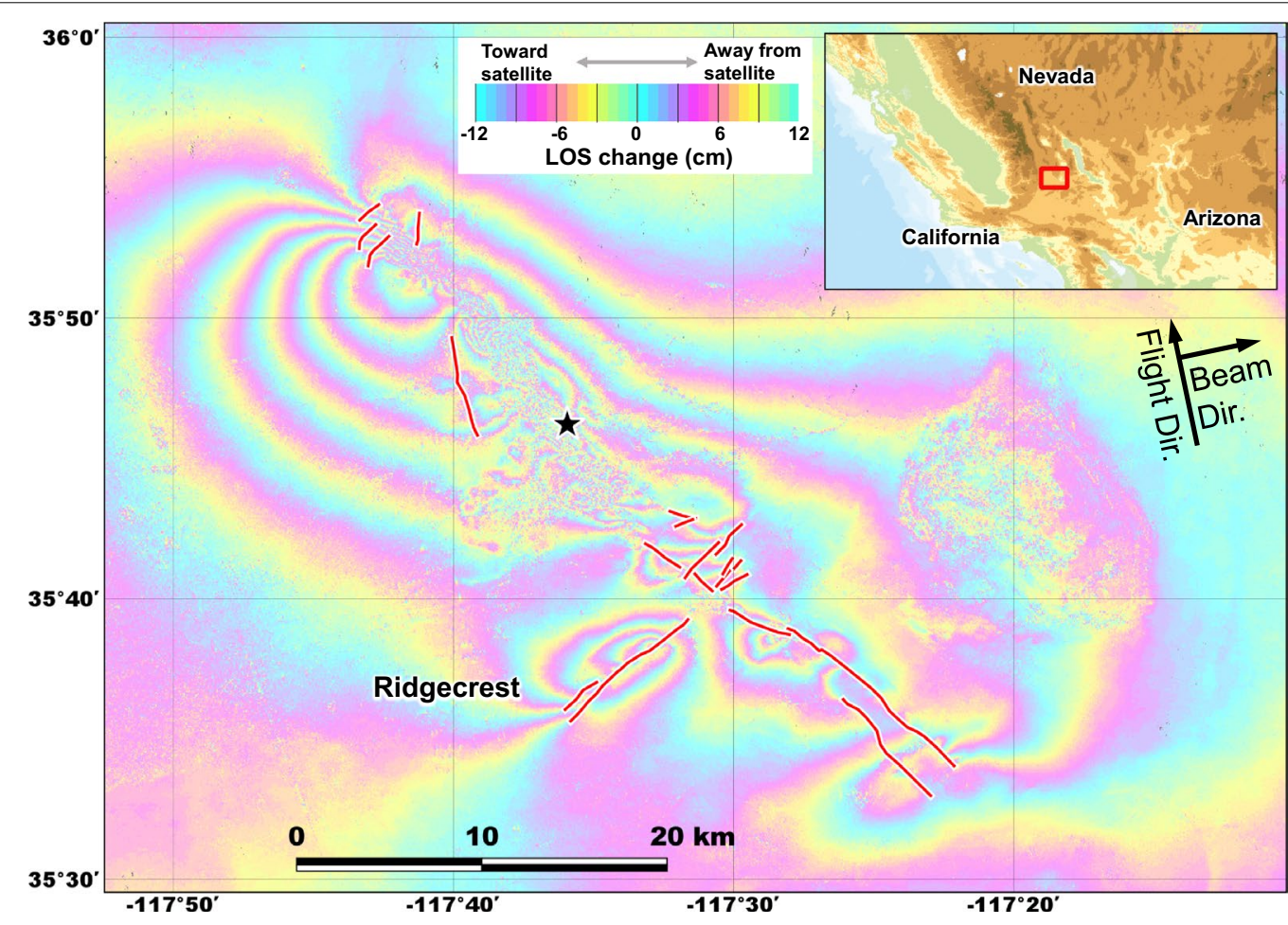

Fig. 11 Interferogram depicting the displacement lineaments caused by the Ridgecrest earthquake sequence of 2019. The interferogram was constructed using ALOS-2 data captured between August 12, 2017, and July 13, 2019 (Geospatial Information Authority of Japan 2019). Red lines indicate the displacement lineaments identified in this study. The star indicates the epicenter of the main shock 

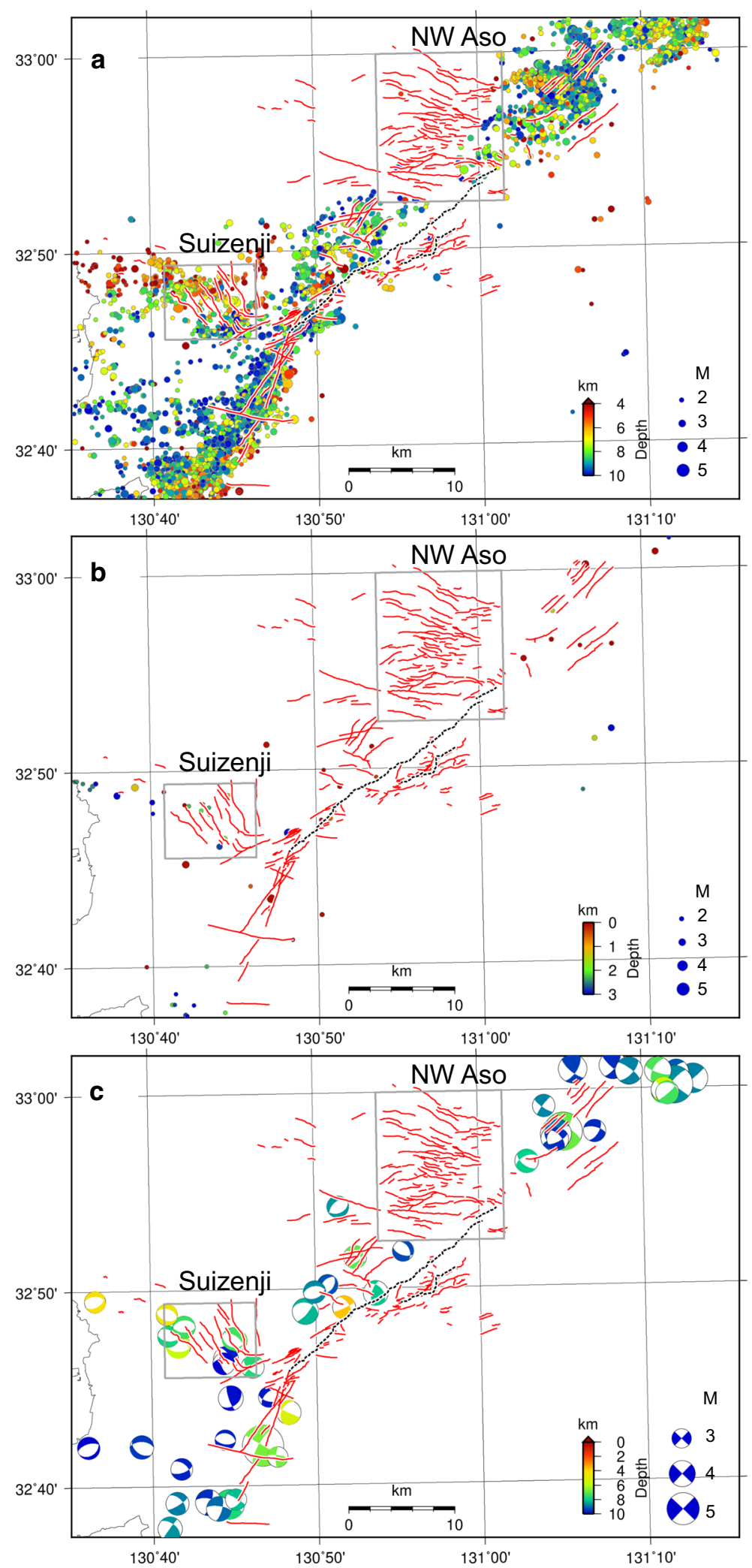

Fig. 12 Epicenters and focal mechanisms of shallow earthquakes occurring between April 14 and December 31, 2016. a Epicenters ( $M>1.5$; $0 \mathrm{~km}<$ Depth $<10 \mathrm{~km}$ ). b Epicenters $(M>1.5 ; 0 \mathrm{~km}<$ Depth $<3 \mathrm{~km})$. $\mathbf{c}$ Focal mechanisms $(M>3.0 ; 0 \mathrm{~km}<$ Depth $<10 \mathrm{~km})$ 


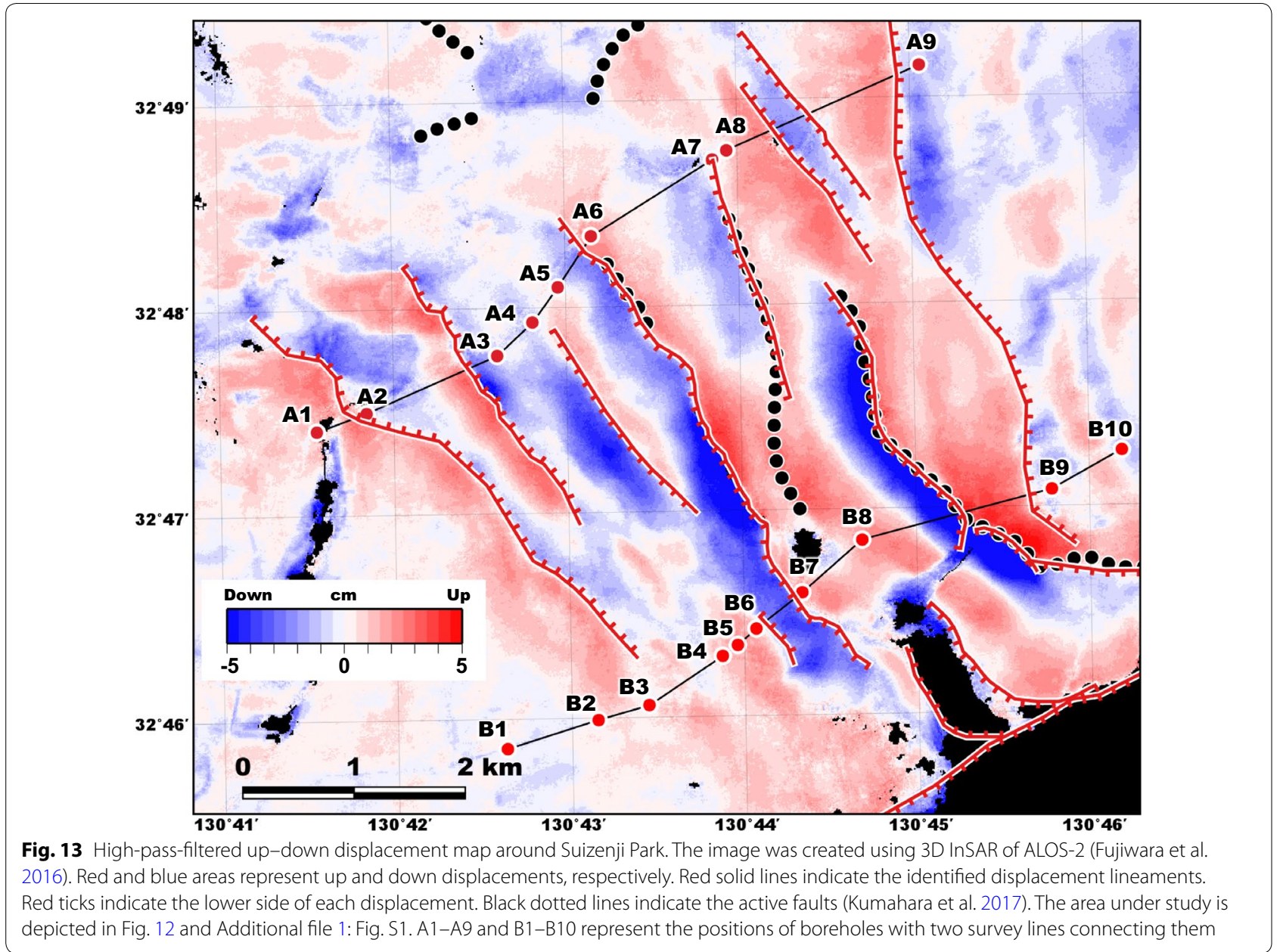

reported existence of up to 10 known active faults in this region. These faults (belonging to the Kuradake fault group) are characterized by graben landforms, and the positions and directions of the known active faults coincide with those of DLs (Fujiwara et al. 2016; Fig. 6).

In this study, the existence of a correlation between topography and vertical displacement can be realized. For example, the 2-km horizontal distance in Fig. 17b shows that the difference in height (topography) equals approximately $50 \mathrm{~m}$, and the vertical displacement equals approximately $50 \mathrm{~cm}$. If the same displacement value is recorded for each historical earthquake, it would require at least 100 such earthquakes to build the current topographic relief. This correlation between slip displacements and topography suggest that earthquakes occurring in regional tectonic stress fields tend to cause similar DLs at identical positions resulting in the formation of the observed topography (Fujiwara et al. 2000a).

There exist several parallel faults along the E-W direction in central Kyushu between the Beppu Bay and Unzen (Chida 1992). NW-Aso (the Kuradake fault group) is located near the center of this characteristic region. Figure 18a depicts the Haneyama-Kuenohirayama fault zone (located approximately $30 \mathrm{~km}$ north of the Kuradake fault group). To facilitate comparison between the two fault groups, Fig. 18b depicts DLs demonstrating normal fault movements with identical to those of corresponding movements observed in NW-Aso. As observed in both groups, the northern and southern parts mainly comprise dip-slip displacements with the corresponding southern and northern sides exhibiting downward movement, respectively. This suggests that fault groups in central Kyushu were formed via similar mechanisms. Based on the similarity between the Kuradake fault group and the Haneyama-Kuenohirayama fault zone, the occurrence of large earthquakes in faults such as the Futagawa fault zone (the main earthquake fault) likely triggered movements of surrounding DLs. Some of the remaining N-S extension strain in the shallow area is likely released in the normal fault group in central Kyushu. In addition, these 


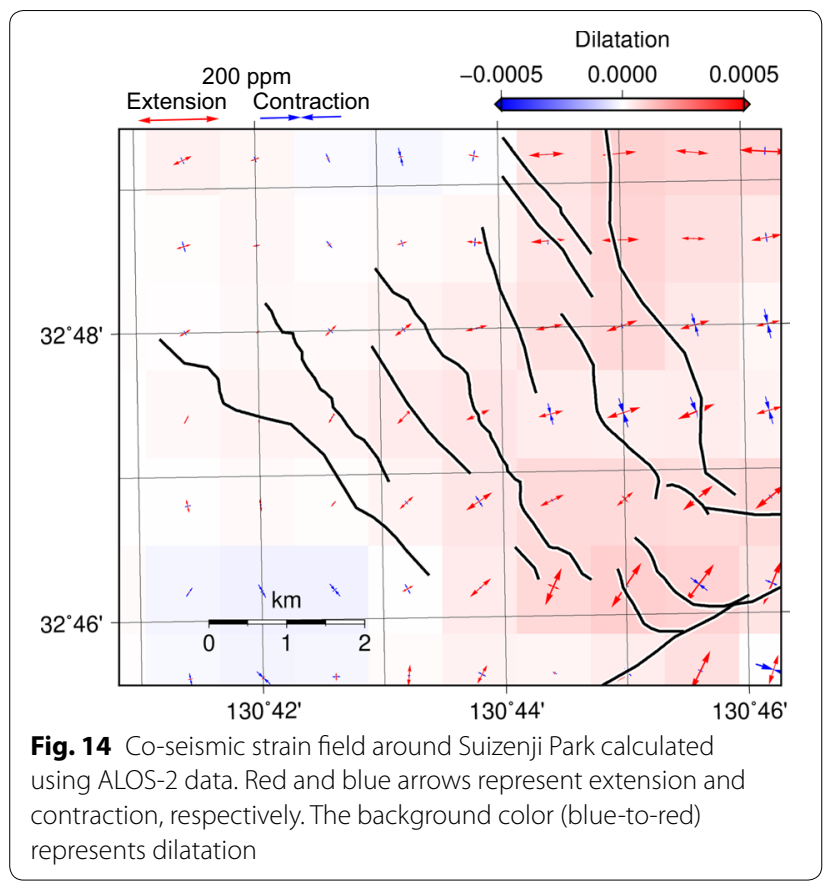

normal fault groups exist near regions of volcanic activity, and together with wide-range stress-field characteristics, this can be considered a unique but typical geological feature of central Kyushu.

Figure 19a depicts the difference between $\mathrm{N}-\mathrm{S}$ components of horizontal displacements to the north and south of each DL. This difference in displacements corresponds to N-S opening displacements at each DL. Figure 19b illustrates surface strain and dilatation values calculated using the 3D deformation map (Additional file 1: Fig. S2). As can be observed, strain distributions in the southern and eastern parts of Fig. 19b demonstrate greater variation from place to place compared to other regions owing to the southern region's proximity to the Futagawa fault and the occurrence of local lateral spreading in the eastern region (Fujiwara et al. 2017a). In the central region, $\mathrm{N}-\mathrm{S}$ extension is dominant around "Ext." in Fig. 19b, whereas an N-S contraction exists around "Cont." This can be attributed to the greater northward movement of the southern part of "Cont." compared to other regions. Interestingly, DLs in "Cont." moved to open $\mathrm{N}-\mathrm{S}$ direction (Fig. 19a) despite the shortening of the strain in this direction (Fig. 19b). This is because, in this study, strain was calculated by averaging surrounding crustal deformation data, thereby resulting in an effect similar to that of low-pass-filtered displacement; the strain represents a somewhat broader force than the ones that DLs were receiving directly. (Figure 19a). In addition, DL movement observed in this study does not coincide with delta CFF caused by main seismogenic faults. In particular, at greater depths (of the order of $2 \mathrm{~km}$ ), there exists a force that further restrains DL movement (Additional file 1: Fig. S4). Therefore, it is important that some DLs do not correspond to the strain caused by the Kumamoto earthquake sequence. In other words, the static displacement caused by the earthquake does not directly shift DLs in NW-Aso. The observed slip in each DL is likely triggered by dynamic shaking encountered during passage of seismic waves (Kaneko et al. 2015). Thus, it can be inferred that uniform DLs around the Suizenji Park are caused by the systematic and simple strain field that exists therein, while uniform DLs in NW-Aso appear to have been caused under a complex strain field caused by the Kumamoto earthquake sequence. These contrasting stress fields may consider the cause of the completely different DL movements observed at these locations.

\section{Discussion}

Previous studies have shown that DL is not necessarily associated only with large earthquakes and that it can also occur spontaneously and/or episodically (e.g., Bilham et al. 2016; Nishimura et al. 2008; Wei et al. 2009). However, in this study, we found no examples of numerous DLs moving aseismically at nearly the same time. In the meantime, the DLs seen in radar interferograms can be caused not only by TSS, but also by the deformation of the fault zones that have reduced the effective rigidity compared to the intact crust (e.g., Fialko et al. 2002; Hamiel and Fialko 2007). In this case, the feature in the interferogram does not show a steep phase discontinuity but a phase variation zone with some width. If the top of a fault does not reach the ground, the interferogram shows a similar variation zone, and in this case, it is difficult to distinguish between these two phenomena. Since both of these displacements coseismically occur in a mechanically weak place such as a fault, we treat them as TSSs in this study.

In view of the above results and that of Fujiwara et al. (2019), most DLs can be considered TSSs because most of the DLs appear during large earthquakes. In the following discussion, we assume DLs to be generated by TSSs.

\section{TSS depth estimation}

In NW-Aso, the eastern side comprises the caldera wall, and some DLs appear to extend from the top to the bottom of this wall (Fig. 6). Since the caldera wall is approximately $400-\mathrm{m}$ tall, the overall depth of TSSs can be considered to exceed $400 \mathrm{~m}$ when measured from the ground surface. To investigate the relationship between the TSS-bottom depth and the horizontal range of DLs, simple and preliminary model simulations were performed by changing the TSS-bottom depth (Additional 


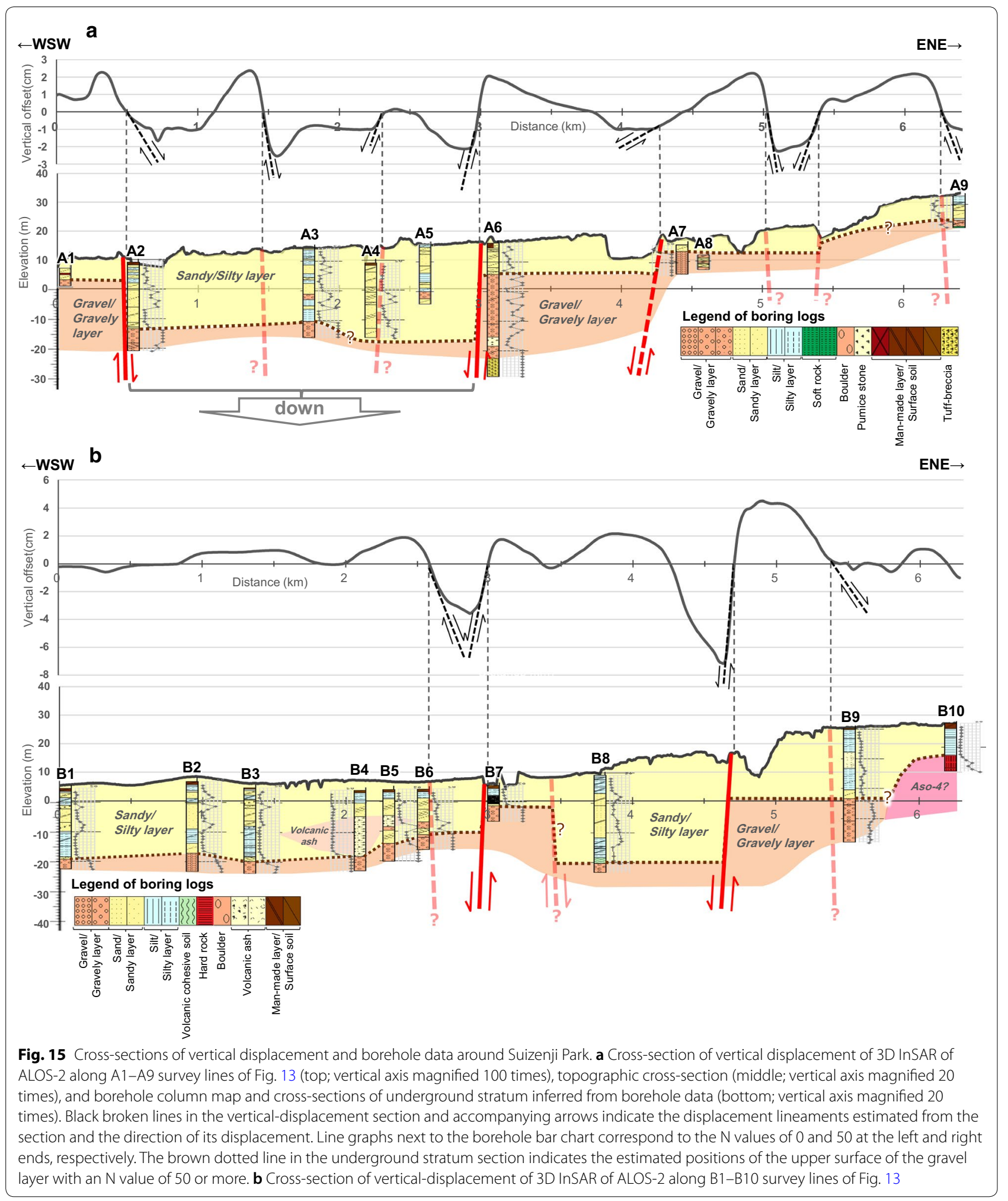

file 1: Fig. S5). The simulation results reveal that the TSS-bottom depth and horizontal range of the displacement are nearly identical, and the horizontal crustal deformation does not extend more than several kilometers as the observation. Therefore, based on the extent of horizontal displacement depicted in Fig. 16a, typical 

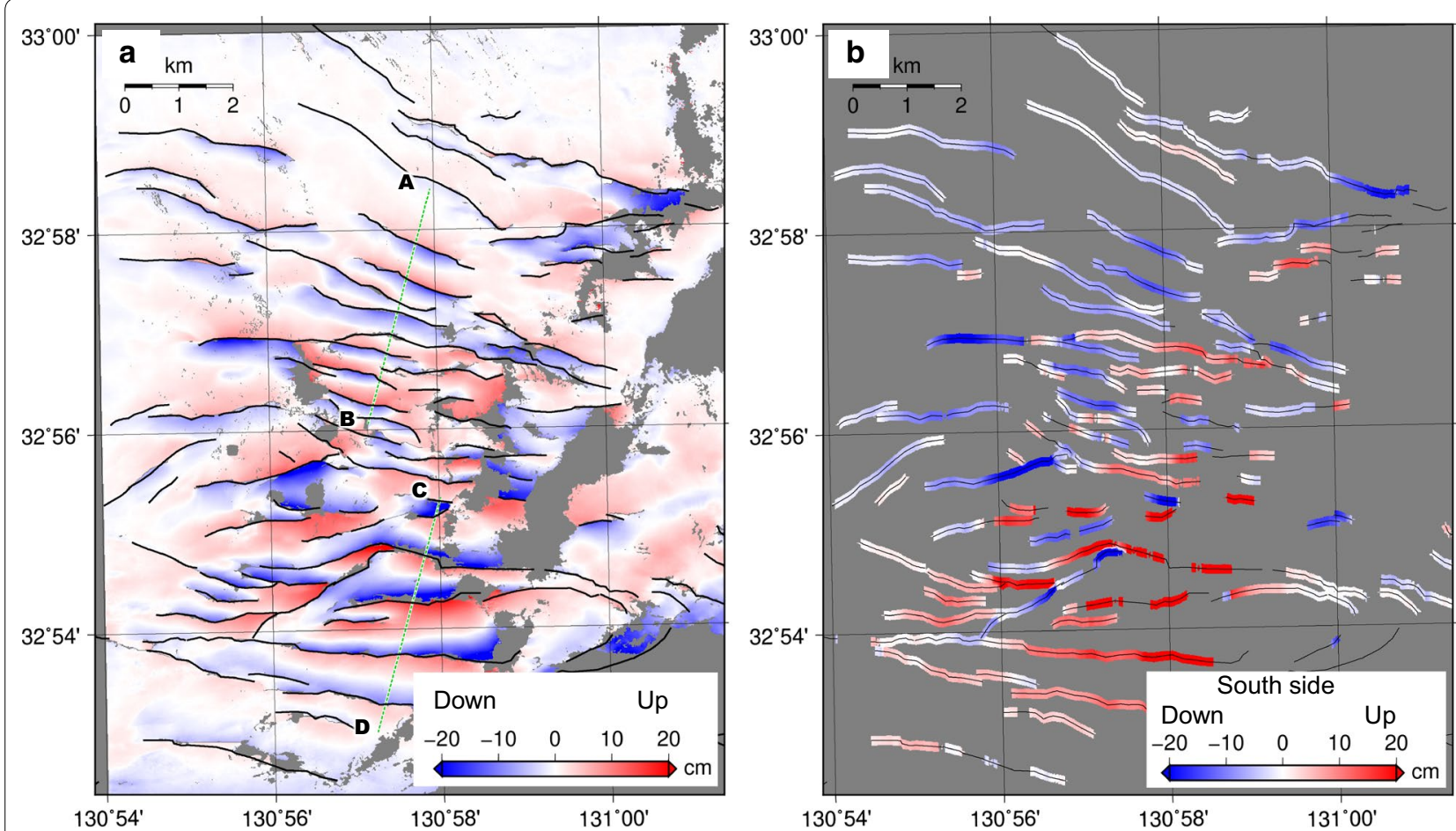

Fig. 16 Displacement lineaments and up-down map around the northwest of outer rim of Aso caldera. The area under study is depicted in Figs. 12 and Additional file 1: S1. a High-pass-filtered up-down displacement map created using 3D InSAR of ALOS-2 (Fujiwara et al. 2016). Red and blue areas represent up and down displacements, respectively; black solid lines indicate the identified displacement lineaments; A-B and C-D represent the cross-sections depicted in Fig. 17. b Map of difference in vertical displacement between northern and southern sides along each displacement lineament. Black solid lines indicate the identified displacement lineaments

TSS-bottom depths can be expected to measure between several hundred meters and several kilometers.

In general, earthquakes follow a scaling law, according to which the displacement and width increase corresponding to an increase in fault length (for dip-slip faults, the width is between the top and bottom of a fault and is related to their bottom depths; Fujii and Matsu'ura 2000; Matsuda 1975). Figure 16b depicts the vertical difference at each TSS. However, this figure does not reveal the existence of a relationship between fault length and displacement, and it can be considered that the scaling law is inapplicable for TSSs. It is suggested that a TSS cannot crack below a certain depth, and its width cannot increase in proportion to its length. Because the scaling law is invalid, a TSS is different from a general seismic fault.

\section{TSS distribution characteristics and defining factors}

This section discusses the occurrence of several uniform and parallel TSSs in each region.

We suggest that there exists a limit to the maximum displacement of each region, irrespective of the corresponding TSS length. Figures 16 and 17 reveal the existence of a greater maximum displacement in the southern part. Further, many TSSs are concentrated in a narrow space at the center of Fig. 16 (southern part of cross-section $\mathrm{A}-\mathrm{B}$ ). In this region, the distance between adjacent TSSs and their corresponding displacements are small. A comparison of the north $(\mathrm{A}-\mathrm{B})$ and south $(\mathrm{C}-\mathrm{D})$ crosssections depicted in Figs. 16a and 17 reveals that the horizontal distance (spacing) between adjacent TSSs is greater in the southern cross-section, and so is the corresponding displacement. Average TSS displacements in the northern and southern cross-sections depicted in Fig. 17 measure approximately $15 \mathrm{~cm}$ and $27 \mathrm{~cm}$, respectively, with the corresponding average horizontal distances measuring $640 \mathrm{~m}$ and $920 \mathrm{~m}$, respectively. In view of this result, we postulate that there exists a correlation between TSS spacing and corresponding displacement. Based on these findings and the estimation of TSS depth, the following hypothesis was considered in this study.

In a particular region, each TSS is characterized by a maximum depth limit that determines the width of the fault plane and the maximum displacement of each TSS. Subsequently, the maximum strain release per unit TSS length can be determined. The horizontal distribution area of TSSs corresponds to the strain-release area, and the length of each TSS does not necessarily depend on the total strain released. 

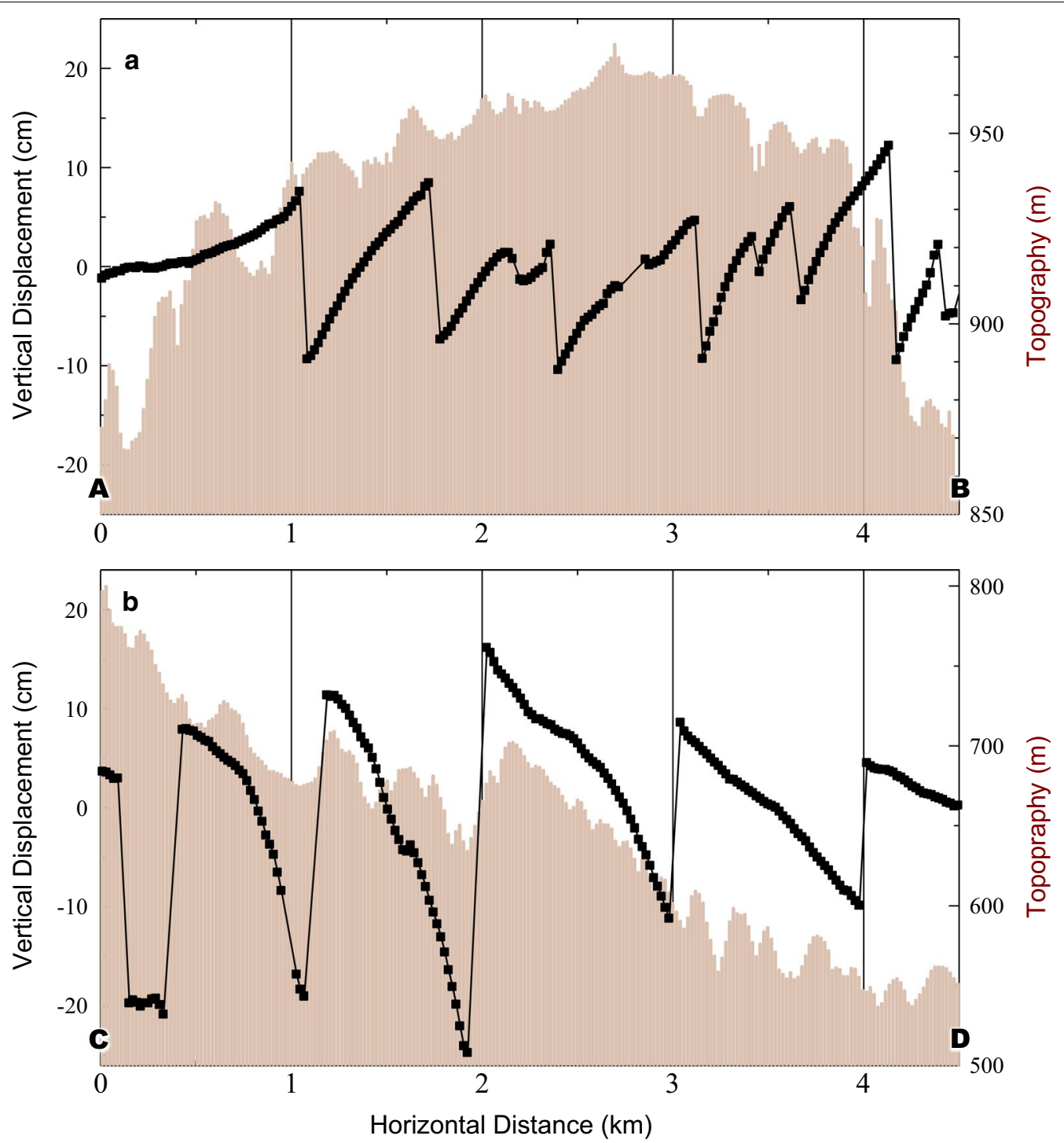

Fig. 17 Cross-sections of the vertical displacement and topography of positions A-B and C-D depicted in Fig. 16

In accordance with this hypothesis, when a single TSS cannot fully release the strain within a certain area (because it does not crack to a sufficient depth), the appearance of multiple parallel TSSs can be explained because TSS length alone does not provide enough strain release. In other words, it is not only the strain field but also the TSS-bottom depth that defines TSS distribution and displacement magnitude. Further, under a constant strain, the greater the maximum TSS-bottom depth, the greater the strain released per TSS. This results in a larger TSS spacing, because the total strain can now be released with a smaller number of parallel TSSs.

The most important question now is, how exactly is the maximum TSS-bottom depth regulated? This can be explained based on the following three hypotheses.
(1) Some geological boundaries may exist at certain depths. Because this is a simple and easy-to-understand reasoning, no detailed seismic exploration has been performed in NW-Aso and its verification has not yet been completed.

(2) There may exist differences in values of tectonic stress between shallow and deep regions. Around Suizenji Park, smaller values of delta CFF were observed at a $2-\mathrm{km}$ depth compared to that at ground surface (Additional file 1: Fig. S3) whereas in NW-Aso, increasingly negative delta CFF values were observed (stress change likely prevents TSS motion) at $2 \mathrm{~km}$ compared to the ground surface (Additional file 1: Fig. S4). 


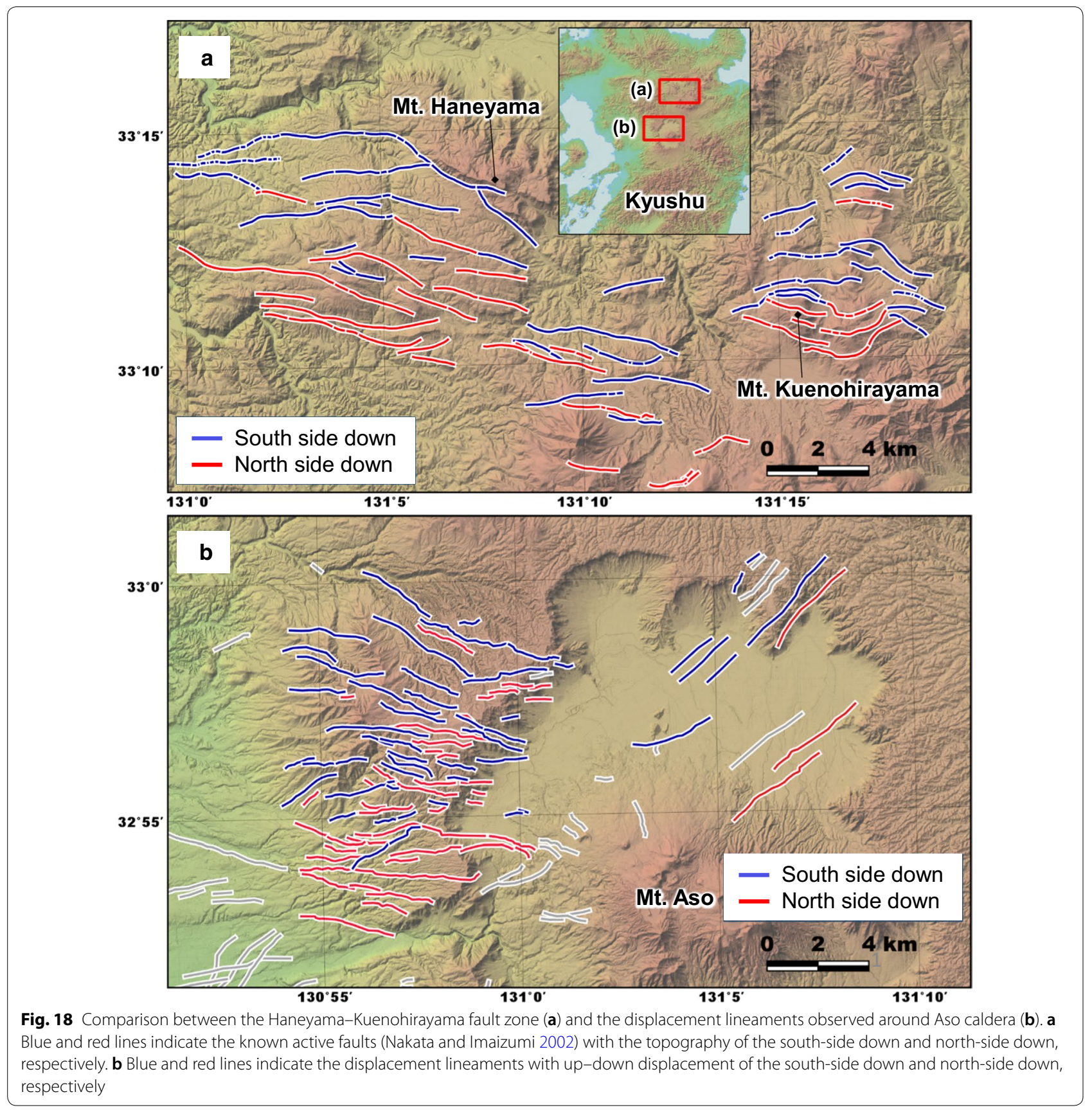

(3) Deeper TSSs tend to be more rigid compared to shallow TSSs, thereby requiring greater stress release to facilitate movement. In general, a stable velocity-strengthening layer exists on top of the unstable velocity-weakening layer that causes earthquakes (e.g., Scholz 1998) and the depth of a shallow slip is controlled by the thickness of the velocitystrengthening layer above the seismogenic zone.

A second important question concerns the existence of a causal relationship between TSS spacing and its displacement. Since there exists a correlation between TSS displacement and topography of known active faults (Fig. 17; Fujiwara et al. 2016), TSS occurrence has been likely observed at pre-existing crack locations. Therefore, the horizontal spacing of TSSs observed in this study via satellite images was fixed before earthquake occurrence. Consequently, regular and uniform displacements (Fig. 17) were observed despite TSS positions being predetermined. Therefore, it is most natural to think that large earthquakes have occurred repeatedly in the past 


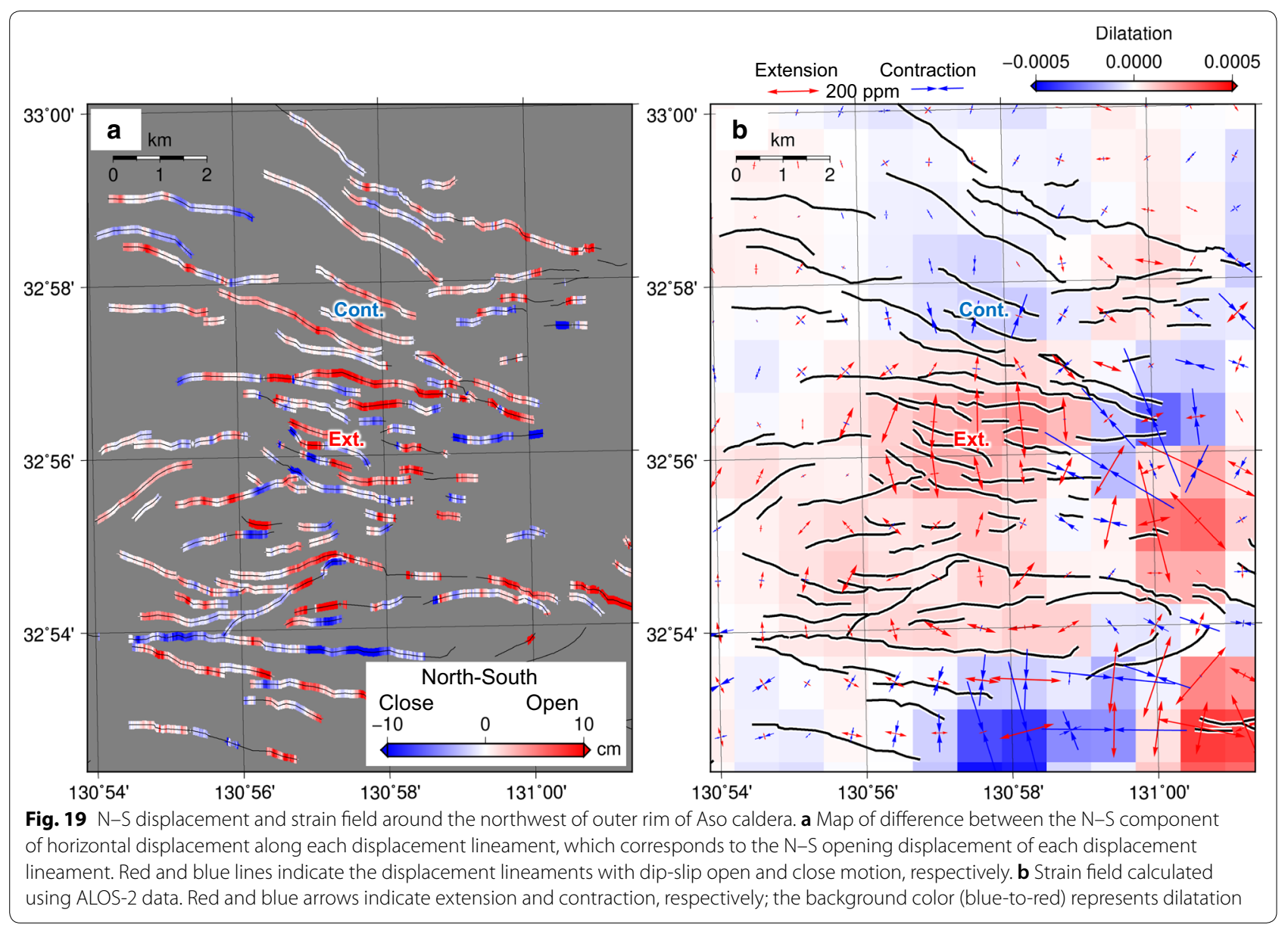

causing similar DL displacements. This raises the question as to how the first TSS group was created. Because TSSs in NW-Aso subtend an acute angle with respect to the Futagawa fault, we suggest they can be considered Riedel shear structures (e.g., Tchalenko 1970) with the Futagawa fault zone being the main fault. In any case, there exists some relationship between TSS distribution and its displacement, depth, and horizontal spacing.

Because the above discussion is rather preliminary and based on the assumption of uniform displacement on a fault plane of TSS, detailed simulations and further observations need to be performed for other earthquakes to answer the questions raised above.

\section{Driving force of TSSs}

Let us first consider the possibility of TSSs being driven by aftershocks. We have estimated one of the largest moment magnitudes of aftershocks caused by TSS motion, as described in Fig. 16. When a TSS measuring $5 \times 1 \mathrm{~km}^{2}$ (length $\times$ width) slips $50 \mathrm{~cm}$ with a rigidity of $30 \mathrm{GPa}$, the resulting moment magnitude equals 5.2. However, because TSSs are generally shallow, the assumption of a very low rigidity (0.1 GPa; Sharma et al. 2011) yields a moment magnitude of 3.5 .

In the analyses performed in this study, no aftershocks with $M_{\mathrm{w}}$ values exceeding 3 were observed at TSS locations corresponding to the Kumamoto earthquake sequence (Fig. 12). In addition, Fujiwara et al. (2000a) pointed out the existence of no aftershocks explaining the length of the TSS caused by the Northern Iwate earthquake. Aftershocks and the main shock would not have been separated by seismic observations if they occurred simultaneously or if the previously mentioned dynamic shaking triggered TSS motion. Figure 12b shows that the number of earthquakes occurring at a depth shallower than $3 \mathrm{~km}$ is very small; further, it is unlikely that an earthquake of such magnitude $(M>3)$ will frequently occur in a shallow place (several hundred meters to a few kilometers). Therefore, most of the TSSs cannot be formed by aftershocks. However, around the Suizenji Park, it can be considered that the strain at greater depths and shallow regions was released via aftershocks and TSS creation, respectively. 
A comparison of TSSs occurring in the Suizenji Park and NW-Aso owing to the same Kumamoto earthquake sequence reveals a clear difference in their formation mechanism. The Suizenji Park region is characterized by the occurrence of both aftershocks and post-seismic deformations, none of which occurred in NW-Aso (Figs. 12 and Additional file 1: S1). In addition, TSSs around Suizenji Park are characterized by shapes consistent with the co-seismic strain field caused by the Kumamoto earthquake sequence (Fig. 14). In NW-Aso, however, the static crustal deformation field cannot completely account for the displacements observed therein (Fig. 19). Repeated triangulation surveys conducted for approximately 100 years in the central Kyushu study region have revealed the existence of the conspicuous $\mathrm{N}-\mathrm{S}$ extensional stress field (Tada 1984). In view of these findings, TSSs observed in NW-Aso, albeit triggered by the Kumamoto earthquake sequence, cannot be considered to have been caused by it. Instead, they are likely caused by the release of tectonic crustal strains accumulated over a long period. However, the local strain of the ENE-WSW extension around TSSs observed in the Suizenji Park is most likely an effect of the Futagawa fault movement caused by the Kumamoto earthquake sequence. TSS movements caused by both the Northern Osaka and Hokkaido Eastern Iburi earthquakes were observed to be consistent with the wide-area strain field. In other words, although the TSS movement around Suizenji Park appears simple, it is a special case among the different TSSs considered in this study. In addition, even if the cause of the stress that drives TSSs is different in each area, identical active fault topographies are formed in each region, thereby indicating the occurrence of similar movements in the past regardless of the cause of TSSs.

\section{General nature of TSSs}

Based on the results obtained in this study and those reported by Fujiwara et al. (2016), (2019), the common features of TSSs can be listed as follows:

(1) A typical TSS is several kilometers or more in length and possesses a linear or gentle curvilinear shape; its displacements measure from a few to several tens of centimeters.

(2) The depth of a typical TSS measures between several hundred meters and several kilometers.

(3) Most TSSs get distributed away from seismogenic faults and are seldom directly connected.

(4) There is no evidence that TSSs generate strong seismic waves at the time of the main earthquake; that is, TSSs may move "slowly" without generating large seismic waves.
(5) TSSs move passively and are considered to be the results, not the cause, of the main earthquake.

(6) Since there exists a correlation between TSS displacement and the topography of certain regions, some TSSs have been recognized as active faults based on their topographical features. Thus, similar TSS movements have occurred at the same place in the past.

(7) TSS strike directions and displacement patterns are consistent with the surrounding stress field over a wide region or the secondary stress field caused by a major earthquake fault nearby. Therefore, TSS shapes observed at a specific location are not random but aligned with each other.

(8) Faults that have caused $M 7$-class earthquakes in the past can also form TSSs associated with other small earthquakes.

The above results lead to the following hypotheses. Before DL movement, the strain becomes larger around the DL due to wide-area stress-field accumulation or the fault motion of a nearby large earthquake. A large earthquake nearby triggers the movement of TSSs by static stress change and/or dynamic shaking during the passage of seismic waves. Subsequently, TSSs move without generating large seismic waves, and the accumulated strain is released via fault motions and thus forms DLs. TSS movements are limited to shallow regions, and only shallow places undergo fault movements. Once such faulting occurs, a TSS manifests itself as a weak fault plane that is easy to move. In the future, such faults planes can be considered to move repeatedly at the same location. These hypotheses must be validated by examining TSSs pertaining to other earthquakes.

\section{Concluding remarks}

To facilitate disaster mitigation, it is common practice to evaluate the occurrence of future large earthquakes based on the accumulated displacement of active faults. This study reveals that crustal deformations accumulated in a topography not only include seismic fault movements that cause large earthquakes but also DLs caused by TSS movement without large seismic motion. In other words, it is not possible to determine whether extant displacements have been caused by main earthquakes, TSSs, or both. Therefore, researchers need to be wary of the diversity of active faults. This study reveals the occurrence of similar TSSs caused by the same trigger, such as the Kumamoto earthquake sequence. However, driving forces that cause these TSSs can be completely different, yet the TSSs may remain physically identical to each other. 
In addition, as observed in this study, the creation of each L-band InSAR image results in the obtainment of new knowledge pertaining to earthquakes. Therefore, it is clear that only partial knowledge of active faults is currently available, and that L-band InSAR is a useful technique to explore active faults and earthquakes in future research endeavors. We believe that the most critical factor for evaluating earthquake diversity is to observe more cases around the world, and using L-band InSAR, researchers can analyze crustal deformation caused by large earthquakes.

\section{Supplementary information}

Supplementary information accompanies this paper at https://doi. org/10.1186/s40623-020-01239-6.

Additional file 1: Fig. S1. Interferogram of ALOS-2 indicating the postseismic deformation that occurred between April 17 and May 1, 2016. Small lines show the displacement lineaments identified by Fujiwara et al. (2016) and modified in this study using ALOS-2 interferograms. Fig. S2. 3D deformation map of the Kumamoto earthquake sequence using ALOS-2 InSAR. The blue-to-red map shows the vertical displacement with arrows indicating horizontal displacement. Black lines indicate the displacement lineaments identified by Fujiwara et al. (2016) and modified in this study. Fig. S3. Static Coulomb stress changes resolved on the displacement lineament mechanism. The colors indicate the amount of calculated delta CFF on typical displacement lineaments around Suizenji Park (strike $150^{\circ}$, dip $90^{\circ}$, rake $270^{\circ}$, (a) depth $0 \mathrm{~km}$, (b) depth $2 \mathrm{~km}$ ). The seismogenic fault model of the Kumamoto earthquake sequence was adapted from Kobayashi et al. (2018b). Fig. S4. Static Coulomb stress changes resolved on the displacement lineament mechanism. The colors indicate the amount of calculated delta CFF on typical displacement lineaments around the northwest of the outer rim of Aso caldera (strike $100^{\circ}$, dip $90^{\circ}$, rake $270^{\circ}$, (a) depth $0 \mathrm{~km}$, (b) depth $2 \mathrm{~km}$ ). The seismogenic fault model of the Kumamoto earthquake sequence was adapted from Kobayashi et al. (2018b). Fig. S5. Comparison between up-down displacement and model simulations of displacement lineaments. (a) High-pass-filtered updown displacement map created using 3D InSAR of ALOS-2 (Fujiwara et al. 2016). Red and blue areas represent up and down directions, respectively; black lines indicate identified displacement lineaments. (b) Model simulation of three parallel displacement lineaments (black lines) for a 2-km width (length $5 \mathrm{~km}$, horizontal spacing of each displacement $670 \mathrm{~m}$, strike $100^{\circ}$, dip $90^{\circ}$, rake $270^{\circ}$, slip $50 \mathrm{~cm}$ ) using the same high-pass filter as in (a). (c) Model simulation for a 0.5-km width, similar to (b).

\section{Abbreviations}

CFF: Coulomb failure function; InSAR: Interferometric synthetic aperture radar; LOS: Line-of-sight; DL: Displacement lineament; NW-Aso: Northwest of the outer rim of Aso caldera; TSS: Triggered shallow slip.

\section{Acknowledgements}

ALOS-2 data-belonging to JAXA—were provided by the Earthquake Working Group under a cooperative research contract with JAXA. The Geospatial Information Authority of Japan (GSI) obtained the ALOS/PALSAR data through the "Joint Cooperative Agreement between GSI and JAXA for observation of geographic information using ALOS data." Ownership of the ALOS/PALSAR data is retained by JAXA and METI. The authors used the unified hypocenter catalog of the Japan Meteorological Agency.

\section{Authors' contributions}

SF mapped and analyzed displacements and drafted the manuscript. TN analyzed interferograms and geological data. YM analyzed interferograms. All authors have read and approved the final manuscript.

\section{Funding}

This work was supported by the Geospatial Information Authority of Japan.

\section{Availability of data and materials}

The datasets used and/or analyzed during the current study are available from the corresponding author on reasonable request.

\section{Ethics approval and consent to participate}

Not applicable.

\section{Consent for publication \\ Not applicable.}

\section{Competing interests}

The authors declare that they have no competing interests.

Received: 14 February 2020 Accepted: 22 July 2020

Published online: 13 August 2020

\section{References}

Allen C, Wyss M, Brune J, Grantz A, Wallace R (1972) Displacements on the Imperial, Superstition Hills, and San Andreas faults triggered by the Borrego Mountain earthquake. U.S. Geol Surv Prof Paper 787:87-104

Berardino P, Fornaro G, Lanari R, Sansosti E (2002) A New Algorithm for surface deformation monitoring based on small baseline differential SAR interferograms. IEEE Trans Geosci Remote Sens 40:2375-2383. https://doi. org/10.1109/TGRS.2002.803792

Bilham R, Ozener H, Mencin D, Dogru A, Ergintav S, Cakir Z, Aytun A, Aktug B, Yilmaz O, Johnson W, Mattioli G (2016) Surface creep on the North Anatolian fault at Ismetpasa, Turkey, 1944-2016. J Geophys Res 121:7409-7431. https://doi.org/10.1002/2016JB013394

Chida N (1992) Active faults in Central Kyushu, Southwest Japan—quaternary faulting along the Median tectonic line in Kyushu - Mem Geol Soc Jpn 40:39-51 (in Japanese with English abstract)

Earthquake Research Committee (2001) Evaluation of the Arima-Takatsuki fault zone. https://www.jishin.go.jp/main/chousa/katsudansou_pdf/76_arima -takatsuki.pdf. Accessed 13 Dec 2019 (in Japanese)

Earthquake Research Committee (2018) Evaluation of earthquake in the northern Osaka prefecture on June 18, 2018. https://www.jishin.go.jp/main/ chousa/18jul_osaka/index-e.htm. Accessed 13 Dec 2019

Earthquake Research Committee (2020) Evaluation of active faults. https:// www.jishin.go.jp/evaluation/long_term_evaluation/major_active_fault/. Accessed 15 June 2020 (in Japanese)

Ferretti A, Prati C, Rocca F (2001) Permanent scatterers in SAR interferometry. IEEE Trans Geosci Remote Sens 39:8-20. https://doi.org/10.1109/36.89866 1

Fialko Y, Sandwell D, Agnew D, Simons M, Shearer P, Minster B (2002) Deformation on nearby faults induced by the 1999 Hector Mine earthquake. Science 297:1858-1862. https://doi.org/10.1126/science.1074671

Fujii Y, Matsu'ura M (2000) Regional difference in scaling laws for large earthquakes and its tectonic implication. Pure Appl Geophys 157:2283-2301. https://doi.org/10.1007/PL00001085

Fujiwara S, Rosen PA, Tobita M, Murakami M (1998) Crustal deformation measurements using repeat-pass JERS 1 synthetic aperture radar interferometry near the Izu Peninsula, Japan. J Geophys Res 103:2411-2426. https:// doi.org/10.1029/97JB02382

Fujiwara S, Nishimura T, Murakami M, Nakagawa H, Tobita M, Rosen PA (2000a) 2.5-D surface deformation of M6.1 earthquake near Mt Iwate detected by SAR interferometry. Geophys Res Lett 27:2049-2052. https://doi. org/10.1029/1999GL011291

Fujiwara S, Ozawa S, Murakami M, Tobita M (2000b) Estimation of fault positions of the 1995 Hyogo-ken nanbu earthquake using surface displacement gradient detected by SAR interferometry. J Seism Soc J.pn 53:127-136. https://doi.org/10.4294/zisin1948.53.2_127 (in Japanese with English abstract)

Fujiwara S, Yarai H, Kobayashi K, Morishita Y, Nakano T, Miyahara B, Nakai H, Miura Y, Ueshiba H, Kakiage Y, Une H (2016) Small-displacement linear surface ruptures of the 2016 Kumamoto earthquake sequence detected 
by ALOS-2 SAR interferometry. Earth Planets Space 68:160. https://doi org/10.1186/s40623-016-0534-X

Fujiwara S, Morishita Y, Nakano T, Kobayashi T, Yarai H (2017a) Non-tectonic liquefaction-induced large surface displacements in the Aso Valley, Japan, caused by the 2016 Kumamoto earthquake, revealed by ALOS-2 SAR. Earth Planet Sci Lett 474:457. https://doi.org/10.1016/j.epsl.2017.07.001

Fujiwara S, Murakami M, Nishimura T, Tobita M, Yarai H, Kobayashi T (2017b) Volcanic deformation of Atosanupuri volcanic complex in the Kussharo caldera, Japan, from 1993 to 2016 revealed by JERS-1, ALOS, and ALOS-2 radar interferometry. Earth Planets Space 69:78. https://doi.org/10.1186/ s40623-017-0662-y

Fujiwara S, Nakano T, Morishita Y, Kobayashi T, Yarai H, Une H, Hayashi K (2019) Detection and interpretation of local surface deformation from the 2018 Hokkaido Eastern Iburi Earthquake using ALOS-2 SAR data. Earth Planets Space 71:64. https://doi.org/10.1186/s40623-019-1046-2

Fukushima Y, Takada Y, Hashimoto M (2013) Complex ruptures of the 11 April $2011 M_{w} 6.6$ Iwaki earthquake triggered by the 11 March $2011 M_{w} 9.0$ Tohoku earthquake, Japan. Bull Seismol Soc Am 103:1572-1583. https:/ doi.org/10.1785/0120120140

Geospatial Information Authority of Japan (2019) The 2019 California Earthquake: Crustal deformation detected by ALOS-2 data. https://www.gsi. go.jp/cais/topic190712-index-e.html. Accessed 7 Dec 2019

Goto H, Tsutsumi H, Toda S, Kumahara Y (2017) Geomorphic features of surface ruptures associated with the 2016 Kumamoto earthquake in and around the downtown of Kumamoto City, and implications on triggered slip along active faults. Earth Planets Space 69:26. https://doi.org/10.1186/ s40623-017-0603-9

Hamiel Y, Fialko Y (2007) Structure and mechanical properties of faults in the North Anatolian Fault system from InSAR observations of coseismic deformation due to the 1999 Izmit (Turkey) earthquake. J Geophys Res 112:B07412. https://doi.org/10.1029/2006JB004777

Kaneko Y, Hamling IJ, Van Dissen RJ, Motagh M, Samsonov SV (2015) InSAR imaging of displacement on flexural-slip faults triggered by the $2013 \mathrm{M}_{\mathrm{w}}$ 6.6 Lake Grassmere earthquake, central New Zealand. Geophys Res Lett 42:781-788. https://doi.org/10.1002/2014GL062767

Kato A, Ueda T (2019) Source fault model of the $2018 M_{w} 5.6$ northern Osaka earthquake, Japan, inferred from the aftershock sequence. Earth Planets Space 71:11. https://doi.org/10.1186/s40623-019-0995-9

Kobayashi T, Morishita Y, Yarai H, Fujiwara S (2018a) InSAR-derived crustal deformation and reverse fault motion of the 2017 Iran-Iraq earthquake in the northwest of the Zagros Orogenic Belt. Bull Geospatial Info Auth Jpn 66:1-9

Kobayashi T, Yarai H, Kawamoto S, Morishita Y, Fujiwara S, Hiyama Y (2018b) Crustal deformation and fault models of the 2016 Kumamoto earthquake sequence: foreshocks and main shock. In: Freymueller J, Sánchez L, (eds) International Symposium on Advancing Geodesy in a Changing World. International Association of Geodesy Symposia, 149. Springer, Cham, https://doi.org/10.1007/1345_2018_37

Kumahara Y, Okada S, Kagohara K, Kaneda H, Goto H, Tsutsumi H (2017) 1:25,000 Active fault map "Kumamoto (revised ed.)". Geospatial Info Auth Jpn. (in Japanese)

Matsuda T (1975) Magnitude and recurrence interval of earthquakes from a fault. J Seismol Soc Jpn 28:269-283. https://doi.org/10.4294/zisin 1948.28.3_269 (in Japanese with English abstract)

Morishita Y (2019) A systematic study of synthetic aperture radar interferograms produced from ALOS-2 data for large global earthquakes from 2014 to 2016. IEEE J Sel Top Appl Earth Obs Remote Sens 12:2397-2408. https://doi.org/10.1109/JSTARS.2019.2921664

Morishita Y, Hanssen R (2015) Temporal decorrelation in L-, C-, and X-band satellite radar interferometry for pasture on drained peat soils. IEEE Trans Geosci Remote Sens 53:1096-1104. https://doi.org/10.1109/ TGRS.2014.2333814

Morishita Y, Kobayashi T, Yarai H (2016) Three-dimensional deformation mapping of a dike intrusion event in Sakurajima in 2015 by exploiting the right- and left-looking ALOS-2 InSAR. Geophys Res Lett 43:4197-4204. https://doi.org/10.1002/2016GL068293

Morishita Y, Kobayashi T, Fujiwara S, Yarai H (2018) Complex crustal deformation of the 2016 Kaiköura, New Zealand, earthquake revealed by ALOS-2. Bull Seismol Soc Am 108:1746-1756. https://doi.org/10.1785/0120180070

Nakano T, Une H, Yoshida K, Fujiwara S, Kobayashi T (2019) Evaluating earthquake-related ground failure mapping by combined traditional and modern methods. Adv Cartogr GIScience Int Cartogr Assoc. https://doi. org/10.5194/ica-adv-1-14-2019

Nakata T, Imaizumi T (eds) (2002) Digital active fault map of Japan. University of Tokyo Press, Tokyo

National Research Institute for Earth Science and Disaster Resilience (2016) Geo-Station. https://www.geo-stn.bosai.go.jp/. Accessed 18 Dec 2019. (in Japanese)

Nishimura T, Tobita M, Yarai H, Amagai T, Fujiwara M, Une H, Koarai M (2008) Episodic growth of fault-related fold in northern Japan observed by SAR interferometry. Geophys Res Lett 35:L13301. https://doi. org/10.1029/2008GL034337

Okada A, Uemura Y, Togo M, Nakata T, Watanabe M (2008) 1:25,000 Active fault map "Kyoto Seinan-bu (revised ed.)", Geospatial Info Auth Jpn. (in Japanese)

Price E, Sandwell D (1998) Small-scale deformations associated with the 1992 Landers, California, earthquake mapped by synthetic aperture radar interferometry phase gradients. J Geophys Res 103:27001-27016. https:// doi.org/10.1029/98JB01821

Rosen PA, Hensley S, Zebker HA, Webb FH, Fielding EJ (1996) Surface deformation and coherence measurements of Kilauea Volcano, Hawaii, from SIR-C radar interferometry. J Geophys Res 101:23109-23125. https://doi. org/10.1029/96JE01459

Sangawa A, Katurajima S, Miyazaki J (1985) Active faults in the southern part of Suruga bay west coast. Proceedings Seismol Soc Jpn C92. (in Japanese)

Scholz C (1998) Earthquakes and friction laws. Nature 391:37-42. https://doi. org/10.1038/34097

Sharma R, Baxter C, Jander M (2011) Relationship between shear wave velocity and stresses at failure for weakly cemented sands during drained triaxial compression. Soils Found 51:761-771. https://doi.org/10.3208/sandf .51 .761

Shirahama Y, Yoshimi M, Awata Y, Maruyama T, Azuma T, Miyashita T, Mori H, Imanishi K, Takeda N, Ochi T, Otsubo M, Asahina D, Miyakawa A (2016) Characteristics of the surface ruptures associated with the 2016 Kumamoto earthquake sequence, central Kyushu, Japan. Earth Planets Space 68:191. https://doi.org/10.1186/s40623-016-0559-1

Sieh K (1982) Slip along the San Andreas fault associated with the earthquake. U.S. Geol Surv Prof Paper 1254:155-159

Suzuki Y, Ishimura D, Kumaki Y, Kumahara Y, Chida N, Nakata T, Nakano T (2017) 1:25,000 Active fault map "Aso", Geospatial Info Auth Jpn. (in Japanese)

Tada T (1984) Spreading of the Okinawa trough and its relation to the crustal deformation in Kyusyu. J Seismol Soc Jpn 37:407-415. https://doi. org/10.4294/zisin1948.37.3_407 (in Japanese with English abstract)

Tajiri K, Nakayama H, Aramaki S, Furusaswa W, Imaizumi S (1998) A Database system for geotechnical investigation in Kumamoto urban area. J Jpn Soc Eng Geol 39:346-351 (in Japanese)

Tchalenko J (1970) Similarities between shear zones of different magnitudes. Geol Soc Am Bull 81:1625-1640. https://doi.org/10.1130/00167606(1970)81\%5b1625:SBSZOD\%5d2.0.CO;2

Tymofyeyeva E, Fialko Y, Jiang J, Xu X, Sandwell D, Bilham R, Rockwell T, Blanton C, Burkett F, Gontz A, Moafipoor S (2019) Slow slip event on the Southern San Andreas fault triggered by the $2017 M_{w} 8.2$ Chiapas (Mexico) earthquake. J Geophys Res 124:9956-9975. https://doi.org/10.1029/2018 B016765

U.S. Geological Survey (2019) 2019 Ridgecrest earthquake sequence. https:// www.usgs.gov/media/images/2019-ridgecrest-earthquake-sequencejuly-4-2019-july-16-2019-0. Accessed 24 Dec 2019

Wei M, Sandwell D, Fialko Y (2009) A Silent M 4.7 slip October 2006 event of on the Superstition Hills fault, southern California. J Geophys Res 114:B07402. https://doi.org/10.1029/2008JB006135

Xu X, Sandwell D, Smith-Konter B (2020) Coseismic displacements and surface fractures from sentinel-1 InSAR: 2019 ridgecrest earthquakes. Seismol Res Lett. https://doi.org/10.1785/0220190275

Yoshida K, Sekiguchi T, Nakano T (2016) Mapping of surface cracks derived from the 2016 Kumamoto earthquake. J Geospatial Info Auth Jpn 128:201-206 (in Japanese)

\section{Publisher's Note}

Springer Nature remains neutral with regard to jurisdictional claims in published maps and institutional affiliations. 